\title{
Cardiac valve regeneration in adult zebrafish: importance of TGFß signaling in new tissue formation
}

Anabela Bensimon-Brito ${ }^{1 *}$, Srinath Ramkumar ${ }^{1 \#}$, Giulia L. M. Boezio ${ }^{1 \#}$, Stefan Guenther $^{2}$, Carsten Kuenne ${ }^{3}$, Héctor Sánchez-Iranzo ${ }^{4}$, Dijana Iloska ${ }^{5}$, Janett Piesker ${ }^{6}$, Soni Pullamsetti ${ }^{5}$, Nadia Mercader ${ }^{7,8}$, Dimitris Beis ${ }^{9}$, Didier Y. R. Stainier ${ }^{1 *}$

${ }^{1}$ Department of Developmental Genetics, Max Planck Institute for Heart and Lung Research, Bad Nauheim, 61231, Germany

${ }^{2}$ Bioinformatics and Deep Sequencing Platform, Max Planck Institute for Heart and Lung Research, Bad Nauheim, 61231, Germany

${ }^{3}$ Bioinformatics Core Unit, Max Planck Institute for Heart and Lung Research, Bad Nauheim, 61231, Germany

${ }^{4}$ Cell Biology and Biophysics Research Unit, EMBL Heidelberg, Heidelberg, 69117, Germany

${ }^{5}$ Department of Lung Development and Remodeling, Max Planck Institute for Heart and Lung Research, Bad Nauheim, 61231, Germany

${ }^{6}$ Scientific Service Group Microscopy, Max Planck Institute for Heart and Lung Research, Bad Nauheim, 61231, Germany

${ }^{7}$ Institute of Anatomy, University of Bern, 3000 Bern 9, Switzerland

${ }^{8}$ Centro Nacional de Investigaciones Cardiovasculares CNIC, Madrid, 28049, Spain

${ }^{9}$ Developmental Biology, Biomedical Research Foundation of the Academy of Athens, Athens, 11527, Greece

\#These authors contributed equally

*Correspondence to:

Anabela.Bensimon-Brito@mpi-bn.mpg.de; Didier.Stainier@mpi-bn.mpg.de

\section{Summary}

Cardiac valve disease can lead to severe cardiac dysfunction and is thus a frequent cause of morbidity and mortality. Its main treatment is valve replacement, which is currently greatly limited by the poor recellularization and tissue formation potential of the implanted valves. As we still lack suitable animal models to identify modulators of these processes, here we used the adult zebrafish and found that, upon valve decellularization, they initiate a striking regenerative program that leads to the formation of new functional valves. After injury, endothelial and kidney marrow-derived cells undergo cell cycle re- 
entry and differentiate into new extracellular matrix-secreting valve cells. The Transforming Growth Factor beta (TGF $\beta$ ) signaling pathway promotes this process by enhancing progenitor cell proliferation as well as valve cell differentiation. These findings reveal a key role for TGF $\beta$ signaling in valve regeneration and also establish the zebrafish as a model to identify and test factors promoting valve recellularization and growth.

\section{Keywords}

Atrio-ventricular, Valve Interstitial Cells, Valve Endothelial Cells, Endothelium, Whole Kidney Marrow, Extracellular Matrix, Cell ablation, Cell tracing, Cell transplantation, Laser Capture Microdissection

\section{Introduction}

Cardiac valve disease is a major threat to human health worldwide, ultimately leading to heart failure and death. Valve defects affect $1 \%$ of all newborns but can also appear later in life with an incidence of $13.3 \%$ in people older than 75 years (Iung, 2003; Nkomo, et al., 2006; Yutzey, et al., 2014). The majority of diseased valves are not repairable, and the only possible therapy relies on surgical replacement to improve survival and quality of life (van Geldorp, et al., 2013). Due to the obvious lack of biological material, the field has invested in finding alternatives for implants, such as the use of mechanical, synthetic and biological scaffolds (Neuenschwander and Hoerstrup, 2004; Fallahiarezoudar, et al., 2015; Ibrahim, et al., 2017; Goecke, et al., 2018; Motta, et al., 2019). The growth and stability of these scaffolds upon implantation rely on the efficient recellularization of the matrix (VeDepo, et al., 2017; Bouten, et al., 2018), which is challenged by the extreme blood flow-induced mechanical forces exerted on the cardiac valves (Hu, et al., 2001; Yalcin, et al., 2011; Kalogirou, et al., 2014; Boselli and Vermot, 2016; Sotiropoulos, et al., 2016; Wissing, et al., 2017).

Most in vivo models for valve implantology are large animals, such as pig and sheep, due to the need to surgically insert the implants (Quinn, 2013; Tsang, et al., 2016; Kheradvar, et al., 2017). Despite the translational potential of these animal models given their anatomical and physiological similarities with the human heart, working with large animals has multiple ethical and technical limitations. As an alternative, a mouse model of pulmonary cardiac valve transplantation has recently been developed to study the process of recellularization in tissue-engineered cardiac valves (James, et al., 2015). The introduction of this murine model brought the possibility of using multiple genetic tools. However, the need for surgical implantation of the valve brings two main limitations: i) surgery is particularly challenging due to the small size of the animal; ii) the insertion of a foreign body in the heart generally triggers an exacerbated immune response which may mask the molecular factors underlying the physiological process of valve 
regeneration. Furthermore, much like the myocardium and other cardiac tissues, mammalian valves display limited regeneration potential (Poss, 2007). Altogether, it becomes particularly challenging to understand which cells are contributing to repopulate the implanted valve leaflets and which molecular factors modulate this process. Thus, it is vital to develop new animal models to study the mechanisms of valve regeneration.

Zebrafish are outstanding in their regenerative capacity (Gemberling, et al., 2013), and multiple studies using this model organism have contributed to uncovering the underlying mechanisms that lead to complex tissue regeneration and to prompt regenerative strategies in mammals. Additionally, the zebrafish cardiac valves share most developmental and morphological features of the mammalian valves (Walsh and Stainier, 2001; Beis, et al., 2005; Scherz, et al., 2008; Martin and Bartman, 2009; Staudt and Stainier, 2012; Pestel, et al., 2016; Steed, et al., 2016; Gunawan, et al., 2019; Schulz, et al., 2019).

Here we used a genetic ablation protocol to decellularize the zebrafish atrio-ventricular (AV) valve and define the regeneration process leading to the formation of new functional valve leaflets. We show that cardiac valve ablation induces the recruitment of endothelial and kidney marrow-derived cells which differentiate into valve cells and secrete extracellular matrix (ECM) to form new cellularized tissue. Interestingly, transcriptome analysis of the ablated and surrounding tissues shows a reactivation of TGFß signaling which promotes cell cycle re-entry. Moreover, by increasing the expression of the ligand Tgfß1b, we were able to enhance new valve cell differentiation, indicating that TGFß acts as a valve pro-regenerative factor with translational potential. Our model provides a new promising approach to identify the cellular and molecular factors regulating new tissue formation during cardiac valve regeneration.

\section{Results}

\section{Decellularization of the zebrafish atrio-ventricular valve triggers a regenerative program leading to a fully regenerated valve}

As in mammals, adult cardiac valves in zebrafish are composed of endothelial cells that surround the extracellular matrix secreted by valve interstitial cells (VICs, Figure 1A-B). Taking advantage of the $\operatorname{TgBAC}$ (nfatcl:Gal4ff) transgenic line, which expresses Gal4 in cardiac valve cells during development (Pestel, et al., 2016), together with the Nitroreductase/Metronidazole (NTR/Mtz) system (Curado, et al., 2007; Pisharath, et al., 2007), we are able to decellularize the adult AV valve by promoting apoptosis of the VICs (Figure 1D-G). Cell death can be detected by 24 hours post ablation (hpab), and the percentage of surviving cells decreases to below $20 \%$ from 72 hpab onward (Figure 1E). Transmission electron microscope (TEM) analyses of uninjured and ablated valve leaflets (Figure 1F-G) show the decellularized ECM, debris of the ablated VICs and rounding of valve endothelial cells (VECs) by $48 \mathrm{hpab}$. Interestingly, valve 
decellularization in zebrafish leads to the activation of a regenerative program which results in a newly formed valve with VICs surrounded by ECM (Figure 1H-K). Functional analysis of valve performance by doppler echocardiography in uninjured and at 7 and 14 days post ablation (dpab) shows that decellularization results in valve malfunction and retrograde blood flow in most animals (6/ 8 and $7 / 12$, respectively; Figure S1A-C, Video S1-S3). By 60 dpab, retrograde flow was detected in only 1/9 ablated animals (Figure S1D, D', Video S4), indicating that the regenerative process leads to the functional recovery of the valve leaflets.

To understand the overall process of zebrafish cardiac valve regeneration, we analyzed cell cycle re-entry, cell differentiation and new tissue formation (Figure 2). Using EdU labelling to determine cell cycle re-entry, we identified an acute increase in the number of EdU + cells around the ablated leaflets, peaking at 48-72 hpab (Figure 2A-C). We also detected multiple oval-shaped cells adjacent to the valve leaflets (Figure 2D), a typical morphology of cells re-entering the cell cycle (Théry and Bornens, 2008; Cadart, et al., 2014). Furthermore, we quantified the number of new $n$ fatcl $1+$ cells across all time points to determine the extent of valve cell differentiation (Figure 2E-G). New cells accumulated and appeared multi-layered mainly on the ventricular side of the leaflets (Figure 2E-F, H), a process particularly evident between 7 and $21 \mathrm{dpab}$. The cell differentiation process is accompanied by new ECM secretion, leading to the temporary thickening of the valve leaflets and establishment of a new valve (Figure 2I-N). At 14 dpab, we detected an immature matrix, rich in hyaluronic acid, which subsequently became enriched with Elastin to form a mature, elastic matrix (Figure 2I-L).

\section{New valve cells differentiate from endothelial and kidney marrow derived-cells}

To identify the origin of the new valve cells, we analyzed different endothelial reporter lines and performed cell tracing experiments (Figure 3). Upon analyzing EdU incorporation in various reporter lines at early stages of valve regeneration, we noticed that the majority of the cells re-entering the cell cycle were positive for the flil and $k d r l$ driven endothelial reporters (Figure 3A-B'). To quantify the number of EdU+ cells exhibiting this endothelial origin, we generated a $\mathrm{Tg}($ flila:H2B-GFP) line which allows for a prolonged labelling of endothelial cell nuclei (Figure 3B-C). Also, upon staining with a Fli1 antibody, we found that that all the cells exhibiting nuclear Fli1 immunostaining were $k d r l+$ (Figure 3D-D' '), indicating that the Fli1 antibody is a valid endothelial cell marker in our experimental setup.

To test whether endothelial cells were differentiating to VICs, we took advantage of the Cre/lox system (Sánchez-Iranzo, et al., 2018) and induced reporter recombination in endothelial cells prior valve cell ablation. With this approach, we saw that an average of $10 \pm 6$ fli $1+$ endothelial cells (per section) which recombined to express GFP prior to valve cell ablation became $n$ fatc $1+$ by 14 dpab (Figure 3E-E"'). Therefore, we were 
able to confirm that endothelial cells differentiate to give rise to the new valve cells (Figure 3E-E','). Additionally, we determined the contribution of circulating cells from hematopoietic tissue to cardiac valve regeneration using whole kidney marrow (WKM) as previously described (Traver, et al., 2003). To this end, we transplanted GFP-labelled WKM from a $T g$ (ubi:switch); $T g$ (nfatc1:NTR-mCherry) fish into irradiated $\operatorname{Tg}$ (nfatc1:NTR-mCherry) adult animals prior to valve cell ablation. We found that at 48 hpab some of the EdU+ cells in the AV canal were derived from WKM (Figure 3F-F') and that, although the majority $(86,3 \pm 0.2 \%)$ of the WKM-derived cells were positive for immune cell markers, some of them were negative (Figure $3 \mathrm{G}_{-} \mathrm{G}^{\prime}$ ), suggesting that they might be valve cell precursors. Interestingly at $14 \mathrm{dpab}$ we identified that an average of $6 \pm 2$ (per section) of the $n$ fatc $1+$ cells also derived from WKM (Figure $3 \mathrm{H}-\mathrm{H}^{\prime}{ }^{\prime \prime}$ )' Altogether, these data show that endothelial as well as circulating hematopoietic cells differentiate to new valve cells.

\section{TGFB signaling enhancement increases cell cycle re-entry and differentiation of new nfatc1+ cells during AV valve regeneration}

Once we had defined the main stages of AV valve regeneration, we performed a transcriptome analysis to identify molecular signatures associated with the regenerative process. For this study, we had to take into consideration that the AV valve leaflets are in close proximity to multiple tissues, including the epicardium, myocardium and endocardium. Additionally, multiple cell types can easily access the valve leaflets, including blood, immune and other circulating cells. These points make it particularly difficult to select reporter lines to sort all the possible cell types contributing to zebrafish valve regeneration. Furthermore, the use of dissociation protocols could potentially mask processes, such as endothelial-to-mesenchymal transition (EndoMT) or cell-ECM interactions, which we expected to be relevant for cardiac valve regeneration. Therefore, we decided to use laser capture microdissection (LCM; (Datta, et al., 2015)) to isolate uninjured, 48 hpab and 21 dpab valve leaflets and surrounding tissue (Figure S2A) which included epicardium, myocardium, endocardium as well as circulating cells (Figure S2B). Principal component analysis (PCA; Figure S2C) shows that the 21 dpab samples are more similar to an uninjured condition than to the 48 hpab samples. Gene set enrichment analysis of differentially expressed genes during the regenerative process (Figure S2D) indicate a role the immune system and cell cycle, as well as ECM organization. By selecting VIC specific markers, we observed a clear downregulation upon decellularization at $48 \mathrm{hpab}$, and a relative upregulation at $21 \mathrm{dpab}$ during new valve cell redifferentiation (Figure S2E). Analysis of the $48 \mathrm{hpab}$ samples showed a differential expression of 2115 genes, from which 951 appeared to be upregulated (Figure S2F). In order to identify secreted proteins potentially recruiting new cells to regenerate the ablated AV valve, we compared the list of upregulated genes with the secreted factor genes from the zebrafish matrisome ((Nauroy, et al., 2018); Figure S2G). We identified a 
total of 12 genes, including $\operatorname{tg} f \beta 1 b$, which has previously been described to play a critical role in valve development, specifically in the regulation of EndoMT, as well as in VIC proliferation and differentiation (Mercado-Pimentel and Runyan, 2007; Conway, et al., 2011).

Taking advantage of the highly sensitive RNAscope-based in situ hybridization, we were able to detect $\operatorname{tg} f \beta 1 b$ transcripts in cells surrounding the ablated leaflets at $48 \mathrm{hpab}$ (Figure S3A-B' '). When co-staining for endothelial and immune cell markers, we identified that the majority of the cells expressing $\operatorname{tg} f \beta 1 b$ were endothelial cells (Figure $\mathrm{S} 3 \mathrm{C}, \mathrm{D})$. To further determine the activation of the signaling pathway, we immunostained for pSmad3, a downstream effector of TGFß signaling (Derynck and Budi, 2019) in combination with an endothelial marker (Figure S3E, E') and EdU (Figure $\left.\mathrm{S} 3 \mathrm{~F}, \mathrm{~F}^{\prime}\right)$. We observed that most pSmad3+ cells were Fli1+, and that most of the EdU+ cells were $\mathrm{pSmad} 3+$, suggesting TGF $\beta$ signaling activation in cells potentially contributing to valve regeneration. Therefore, we performed loss- and gain-of-function experiments of TGFß signaling during cardiac valve regeneration to address its role in cell cycle re-entry and new valve cell differentiation (Figure 4). We used the previously validated TGFß inhibitor SB431542 (Jazwinska, et al., 2007; Chablais and Jazwinska, 2012), and generated a heat-shock inducible dominant negative form of the zebrafish Tgfß receptor I, Alk5a (Figure 4A, B). Additionally, we developed a nfatcl driven $\operatorname{tg} f \beta 1 b$ overexpression transgenic line. To validate the inhibition and activation tools, we analyzed the number of pSmad3 + cells around the ablated leaflets at 48 hpab (Figure S4). We confirmed that SB431542 treatment and $\operatorname{tg} f \beta 1 b$ overexpression induced a reduction and increase in the number of pSmad3 + cells, respectively (Figure S4A-E). In fact, $\operatorname{tg} f \beta 1 b$ overexpression (Figure S4D-F) nearly doubled the number of pSmad3+ cells at 48 hpab in comparison to control. For DNalk5a overexpression (Figure S4C, E, H), we submitted the ablated fish to a single mild heat-shock at 20 hpab (Figure 4A).

Quantification of the number of pSmad3 + cells at 48 hpab showed no clear reduction 28 hours after heat shock. Therefore, we validated the effectiveness of this dominant negative protein in vitro (Figure $\mathrm{S} 4 \mathrm{H}$ ). While the zebrafish wild-type protein further increased the endogenous SBE motif-dependent luciferase expression upon TGFß treatment, the dominant negative protein abrogated this response. In parallel, we used as an additional control the previously validated human dominant negative Alk5a (Wieser, et al., 1995) which, like zebrafish DNAlk5a, caused a loss in the response to TGFß. Once these tools were validated, we determined whether TGFß signaling was required for cell cycle re-entry at 48 hpab (Figure 4). Notably, we observed that pharmacological inhibition of TGFß signaling and overexpression of DNalk5a led to a reduction in the number of EdU+ cells by almost 30 and 50\%, respectively (Figure 4C-F). Importantly, $n f a t c 1$-driven overexpression of the $\operatorname{tg} f \beta 1 b$ ligand increased the number of EdU+ cells at $48 \mathrm{hpab}$ by $50 \%$ (Figure $4 \mathrm{C}, \mathrm{G}$ ). It also doubled the number of $n f a t c 1+$ cells at $14 \mathrm{dpab}$ 
(Figure 4H-J), thus promoting valve cell differentiation. Altogether, these data indicate that TGFß signaling promotes valve regeneration.

\section{Discussion}

Since the first description of an artificial valve over 60 years ago (Hufnagel, et al., 1954), surgeons have been moving from the use of mechanical to living cardiac valve prostheses which require recellularization of the matrix and tissue growth (De Visscher, et al., 2010; Weber, et al., 2013; Driessen-Mol, et al., 2014; Tudorache, et al., 2016; Reimer, et al., 2017; Emmert, et al., 2018; Baldwin and Tolis, 2019). By developing the first model of adult cardiac valve regeneration in the highly regenerative zebrafish, we provide new insights into the processes leading to functional re-establishment of the decellularized AV valve (Figure S5), including the origin of new valve cells, the genes involved in recruiting them, and the de novo tissue formation.

\section{Multi-cellular contribution to cardiac valve regeneration}

Multiple cell types have been proposed as VIC precursors, including ECs, myofibroblasts, bone marrow-, peripheral blood-, and adipose-derived stem cells (Schenke-Layland, et al., 2003; Sutherland, et al., 2005; Dohmen, et al., 2006; Schmidt, et al., 2010; Harrington, et al., 2011; Kennamer, et al., 2016). However, most of these cells have never been shown to contribute to valve development or recellularization in vivo except for ECs, the main VIC source in amniotes (Snarr, et al., 2008; Jain, et al., 2011; Wessels, et al., 2012; MacGrogan, et al., 2014; Liu, et al., 2018). We show that upon injury, the endothelium surrounding the leaflets re-enters the cell cycle and acquires a morphology resembling that previously described in highly proliferative embryonic and postnatal mouse valves (Anstine, et al., 2016). Therefore, valve ablation induces endothelial activation similar to what happens during development, resulting in new valve cell differentiation. We also show that cells deriving from WKM, the fish counterpart to the mammalian bone marrow (Traver, et al., 2003), contribute to the formation of new valve cells. This observation is in agreement with previous reports suggesting that the majority of cells repopulating a tissue-engineered valve implant in lamb are blood-derived (Reimer, et al., 2017) and that hematopoietic stem cells (HSC) differentiate to VICs in non regenerating adult mice valves (Visconti, et al., 2006). Therefore, we show the first in vivo evidence that ECs and WKM-derived cells contribute to cardiac valve regeneration. Moreover, we propose that new valve cell differentiation and de novo tissue formation is orchestrated by multiple cell types.

\section{Identifying molecular regulators of new valve cell recruitment}

Recent studies have focused on identifying and supplementing valve scaffolds with molecular factors promoting valve cell recruitment (Jordan, et al., 2012; Jana, et al., 2014). As in other regeneration models, we hypothesized that valve regeneration would 
rely on the reactivation of developmental signaling cues such as BMP, Notch and TGF $\beta$ pathways (Yamagishi, et al., 2009; Conway, et al., 2011; de la Pompa and Epstein, 2012; Kruithof, et al., 2012). By combining a sophisticated approach to microdissect the regenerating tissues with transcriptomic analysis, we identified multiple genes potentially associated with early stages of valve regeneration, including the secreted TGFß ligand $\operatorname{tg} f \beta 1 b$. Despite the fact that TGF $\beta$ signaling deregulation in homeostasis induces pathological phenotypes in cardiac valves, such as ECM calcification (Anderton, et al., 2011; Wirrig and Yutzey, 2014; White, et al., 2015; Dutta and Lincoln, 2018), previous groups suggested that it may have a role in tissue regeneration, EndoMT and valve recellularization (Jazwinska, et al., 2007; Liu and Gotlieb, 2008; Benton, et al., 2009; Deng, et al., 2011; Li and Gotlieb, 2011; Chablais and Jazwinska, 2012). Using multiple genetic tools, we show that TGFß signaling is required at early regeneration stages and its enhancement promotes cell cycle re-entry and new valve cell differentiation. Interestingly, ECs were the main source of the Tgfß1b ligand, as well as the main responders with TGFß signaling activation via Smad3. Therefore, we propose that TGFß signaling regulates EC proliferation and EndoMT in AV valve regeneration in an autocrine manner, promoting VIC differentiation. These data suggest that the regenerative process can be enhanced by manipulation of single molecules, therefore providing new therapeutic targets in cardiac valve replacement.

\section{Formation of new valve tissue}

As opposed to what was initially expected, despite the presence of immune cells within the decellularized ECM (data not shown), the new valve cells do not seem to invade the old matrix. Instead, newly differentiated valve cells use the decellularized matrix as a scaffold to adhere on the ventricular surface of the leaflets and build a new valve. These cells have the ability to secrete ECM components also present in native leaflets, conferring stiffness and the elastic properties needed for the functional recovery of the $\mathrm{AV}$ valve. Overall, the ultimate goal in cardiac valve replacement is to promote endogenous de novo tissue formation. This new tissue ensures growth and maintenance of the biomechanical properties of the valve leaflets particularly relevant for children and young adults due to somatic growth (Driessen-Mol, et al., 2014; Cheung, et al., 2015; David, 2016; Reimer, et al., 2017). Recently biodegradable synthetic matrices have been developed towards promoting new tissue formation and growth of living valves (Bouten, et al., 2012; Kluin, et al., 2017). Since mammalian models display limited regeneration rates, we propose the zebrafish model as a platform to determine the mechanisms underlying the intrinsic ability to form new tissue and grow new valve leaflets.

\section{Acknowledgments}

We would like to thank Jill de Jong and Sean McConnell for insights regarding WKM transplantation; Matteo Perino for the p3TP:Luc2, SV40:hRLuc2 plasmid and Paul 
Martin for the L-plastin antibody; Simon Howard, Radhan Ramadass and all the fish facility staff for technical support; Christian Helker for discussions; João Cardeira da Silva, Inês Cristo, Felix Gunawan, Carol Yang and Honorine Destain for critical comments on the manuscript. Research in the Stainier lab is supported in part by the Max Planck Society and the European Union (ERC).

\section{Author Contributions}

Conceptualization, A.B.B. and D.Y.R.S.; Methodology, A.B.B., S.R., G.L.M.B., S.G., C.K., H.S.I., D.I., J.P. and D.Y.R.S.; Validation, A.B.B., S.R. and G.L.M.B.; Formal Analysis, A.B.B., S.R., G.L.M.B., S.G. and C.K.; Investigation, A.B.B., S.R., G.L.M.B., S.G., J.P., Resources, H.S.I., D.I., S.P., N.M., D.B. and D.Y.R.S.; Writing - Original Draft, A.B.B. and D.Y.R.S.; Writing - Reviewing \& Editing, all; Visualization - A.B.B., Supervision, A.B.B. and D.Y.R.S.; Project Administration, A.B.B. and D.Y.R.S.; Funding Acquisition, D.Y.R.S.

\section{Declaration of Interests}

The authors declare no competing interests. 


\section{Figure Legends}

Figure 1 - Decellularization of the zebrafish atrio-ventricular valve triggers a regenerative program leading to a fully regenerated valve

(A) Schematics of the zebrafish AV valve leaflet depicting the lining VECs and the ECM-embedded VICs. (B, B') Cryosection of $T g$ (nfatc1:NTR-mCherry) heart showing NTR-mCherry expression restricted to the VICs in the AV and bulbo-ventricular (BV) valves; NTR-mCherry expression is not detected in the VECs (arrows). Boxed area shown in B'. (C) Ablation protocol using the NTR/Mtz system. TUNEL detection (D, D') and quantification (E) in ablated hearts shows apoptotic cells only in the valve leaflets. Plot values represent means \pm SEM. TEM analyses of uninjured $(F)$ and 48 hpab $(G)$ valve sections show the morphology of the lining VECs (green) and VICs (red) before and after ablation. Representative images of the AV valve regeneration process illustrating the uninjured valve $(\mathrm{H})$, tissue decellularization $(\mathrm{I})$, formation of new valve leaflets $(\mathrm{J})$ and completion of regeneration $(\mathrm{K})$ with ECM labeled by Elastin antibody. Dashed lines delineate the old valve leaflets. A - atrium, V - ventricle. Scale bars: (A) $50 \mu \mathrm{m},(\mathrm{B}, \mathrm{D}) 200 \mu \mathrm{m},\left(\mathrm{B}^{\prime}, \mathrm{D}^{\prime}, \mathrm{H}-\mathrm{K}\right) 100 \mu \mathrm{m},(\mathrm{F}, \mathrm{G}) 10 \mu \mathrm{m}$.

Figure 2 - Valve regeneration leads to the formation of new valve leaflets through cell cycle re-entry, new valve cell differentiation and ECM secretion

EdU detection at 48 hpab (A, A') and 7 dpab (B) and quantification at multiple stages after cell ablation (C). (D) TEM analysis shows oval-shaped cells (arrowheads) adjacent to the decellularized valve (blue). New valve cell differentiation as observed at $7 \mathrm{dpab}$ (E, E') and 14 dpab (F). Yellow arrowheads point to new $n$ fatcl-cells and white arrowheads point to new nfatcl+ cells. Boxed area shown in E'. (G) Quantification of new nfatc1+ cells in the AV canal. (H) TEM showing new VICs (red) attached to the old matrix (blue) and surrounded by new ECM (arrowhead). Analysis of new ECM deposition at $14(\mathrm{I}), 21(\mathrm{~J})$ and $60(\mathrm{~K})$ dpab through detection of Elastin1 and hyaluronic acid (HABP). (L) Quantification of ECM ratios in the valve leaflets at 14 and $21 \mathrm{dpab}$. TEM images showing VICs (red) secreting ECM (arrowhead) at 14 dpab (M) and fully regenerated valve leaflets at $60 \mathrm{dpab}(\mathrm{N}$; VECs in green). Yellow and pink dashed lines delineate the old and new valve leaflet ECM, respectively. Plot values represent means \pm SEM. ( ${ }^{*} P<0.05, * * P<0.01, * * * P<0.001$ by Mann Whitney test). A - atrium, V ventricle. Scale bars: (A, A', B, E, F, I-K) $100 \mu \mathrm{m}$, (E') $20 \mu \mathrm{m},(\mathrm{D}, \mathrm{H}, \mathrm{M}, \mathrm{N}) 10 \mu \mathrm{m}$.

Figure 3 - New valve cells differentiate from endothelial and kidney marrow-derived cells 
Characterization of EdU co-localization with endothelial reporters (arrowheads) at 48 hpab including kdrl:GFP (A, A') and flia:H2B-GFP (B, B'). (C) Quantification of the percentage of EdU+ cells positive for flia:H2B-GFP. Plot values represent means \pm SEM. (D) Co-localization of $k d r l$ reporter with Flil antibody (arrowheads). Boxed areas shown in D' and D', (E-E',') Cre/lox cell tracing experiments showing contribution of endothelial cells to $n$ fatc $1+$ cells (arrowheads) at $14 \mathrm{dpab}(\mathrm{n}=6)$. Boxed areas shown in E'-E','. WKM-derived cells positive for EdU (F-F') and negative for the immune cell marker L-Plastin (G-G') at 48 hpab. Boxed areas shown in F' and G'. (H-H',') Contribution of circulating WKM-derived cells to new nfatcl+ cells (arrowheads) at 14 dpab $(n=4)$. Boxed areas shown in H'-H',', Dashed lines delineate the valve leaflets. A - atrium, V - ventricle. Scale bars: (A, B, D, E, F, G, H) 100 mm, (A', B', D'-D', , E'E',', F', G', H'-H',') $20 \mu \mathrm{m}$.

Figure 4 - Manipulation of TGFß signaling alters cell cycle re-entry and differentiation of $\boldsymbol{n f a t c 1}+$ cells during cardiac valve regeneration

Schematics of the drug (A) and heat-shock (B) treatments. EdU quantification (C) and detection at 48 hpab in control samples (D), after SB431542 treatment (E) and overexpression of DNalk5a (F) or $\operatorname{tg} f \beta 1 b(\mathrm{G})$. Characterization of new valve cell differentiation at 14 dpab in control $(\mathrm{H})$ and upon continued expression of $\operatorname{tg} f \beta 1 b$ (I, I'). Arrowhead points to new $n$ fatc $1+$ cells. Boxed area shown in I'. (J) Quantification of new $n$ fatc $1+$ valve cells at $14 \mathrm{dpab}$. Plot values represent means $\pm \mathrm{SEM}$. $\left({ }^{*} P<0.05\right.$ by Mann Whitney test). Dashed lines delineate the AV valve leaflets. A - atrium, V ventricle. Scale bars: (D-I) $100 \mu \mathrm{m}$, (I') $20 \mu \mathrm{m}$. See also Figure S4.

Figure S1 - Regenerated valves recover from functional impairment induced by the decellularization protocol.

Doppler echocardiography analysis of cardiac function in an uninjured fish (A, A') showing unperturbed blood inflow (red) and outflow (blue) without signs of regurgitation (see also Video S1). Retrograde blood flow is detected in 6/8 animals at 7 dpab (B; see also Video S2) and 7/12 animals at 14 dpab (C; see also Video S3). (D, D') Clear separation of incoming and outgoing blood in the same specimen at $60 \mathrm{dpab}$, as observed in $8 / 9$ of the ablated animals (see also Video S4). A - anterior, V - Ventral.

Figure S2 - LCM-RNAseq transcriptome analysis.

(A) Scheme of the AV tissues isolated through LCM for RNAseq analysis. (B) Cryosection of myl7: GFP heart showing the endocardium (endo), myocardium (myo) and epicardium (epi) in the vicinity of the AV valve leaflets. (C) PCA analysis of 
RNAseq samples based on DESeq normalized and rlog transformed counts of all genes. (D) Heatmap with cluster and gene set enrichment (GSE) analyses of DEGs with main biological processes regulated in each cluster. (E) Regulation of VIC markers relative to uninjured samples. MA plot from DEGs (F) and list of matrisome secreted factors upregulated at $48 \mathrm{hpab}(\mathrm{G})$, including Tgfß1b. A - atrium, V - ventricle. Scale bar: (B) $100 \mu \mathrm{m}$.

Figure S3 - Cell cycle re-entry is accompanied by an increase in tgfß1b expression and activation of TGFB signaling in endothelial cells

RNAscope in situ hybridization of $\operatorname{tg} f \beta 1 b$ (arrowheads) in heart cryosections in uninjured (A, A') and 48 hpab (B, B', B' ') AV valves. Boxed areas shown in A', B' and B' '. In situ hybridization for $\operatorname{tg} f \beta 1 b$ (arrowheads) co-stained for immune $(\mathrm{C})$ and endothelial cell markers (D). Characterization of TGFß signaling activation by $\mathrm{pSmad} 3$

immunodetection (arrowheads) together with an endothelial reporter (E, E') and EdU (F, $\left.F^{\prime}\right)$. Boxed areas shown in $E^{\prime}$ and F'. Dashed lines delineate the AV valve leaflets. A atrium, V - ventricle. Scale bars: (A, B, E, F) $100 \mu \mathrm{m}$, (A', B', B', C, D, E', F') $20 \mu \mathrm{m}$.

\section{Figure S4 - Validation of the TGFß signaling modulation tools}

pSmad3 detection at $48 \mathrm{hpab}$ to determine levels of TGF $\beta$ signaling activation in controls (A), after SB431542 treatment (B) and overexpression of DNalk5a (C) or $\operatorname{tgf\beta } 1 b$ (D). (E) Quantification of $\mathrm{pSmad} 3+$ cells in the AV canal. $\mathrm{qPCR}$ analysis of mRNA relative fold change (RFC) of $\operatorname{tg} f \beta 1 b(\mathrm{~F})$ and $\operatorname{alk} 5 a(\mathrm{G})$ in the overexpression lines. (H) In vitro luciferase assay of zebrafish Alk5a wild-type and dominant negative proteins, and human ALK5 dominant negative protein in the absence/presence of the TGFß ligand. Plot values represent means \pm SEM. (ns - non-significant, ${ }^{*} P<0.05$ by Mann Whitney test). Dashed lines delineate the AV valve leaflets. A - atrium, V - ventricle. Scale bars: 100 $\mu \mathrm{m}$.

Figure S5 - Zebrafish cardiac valve regeneration model.

AV valve ablation leads to the recruitment of endothelial and kidney marrow cells, which will contribute to the formation of new valve leaflets. TGFß signaling promotes valve regeneration by regulating cell cycle re-entry and consequent valve cell differentiation which leads to new ECM secretion. VIC - valve interstitial cell, VEC - valve endothelial cell, EC - endothelial cell, KM - kidney marrow. Scale bars: $50 \mu \mathrm{m}$. 
Video S1 - Doppler echocardiography analysis of cardiac function in an uninjured fish showing unperturbed blood inflow (red) and outflow (blue) without signs of regurgitation (Related to Figure S1A-A').

Video S2 - Doppler echocardiography analysis at 7 dpab showing retrograde blood (Related to Figure S1B).

Video S3 - Doppler echocardiography analysis at 14 dpab showing retrograde blood (Related to Figure S1C).

Video S4 - Doppler echocardiography analysis at 60 dpab showing a clear separation of incoming and outgoing blood (Related to Figure S1D-D').

\section{STAR Methods}

\section{LEAD CONTACT AND MATERIALS AVAILABILITY}

Further information and requests for resources and reagents should be directed to and will be fulfilled by the Lead Contact, Didier Y. R. Stainier (Didier.Stainier@mpi-bn.mpg.de).

\section{EXPERIMENTAL MODEL AND SUBJECT DETAILS}

\section{Zebrafish and cell lines}

All zebrafish husbandry was performed under standard conditions, according all institutional (MPG) and national ethical and animal welfare guidelines.

Wild-type or transgenic male and female zebrafish used in this study were derived from the AB strain. Animals were used for ablations from 3 to 6 months post fertilization (mpf). Rearing system and incubators were maintained at $28^{\circ} \mathrm{C}$ with a light cycle of 10 hours dark/14 hours light. All transgenic animals were analyzed as hemizygotes except for the UAS:tgfß $1 b$ and the hsp70:DNalk5a strains.

Luciferase assays were performed using HEK-293T cells.

\section{METHOD DETAILS}

\section{Transgenic lines and plasmids}

The following lines were used:

TgBAC(nfatcl:Gal4ff) ${ }^{m u 286}$ (Pestel, et al., 2016) together with $\operatorname{Tg}(U A S: N T R-m C h e r r y)^{c 264}$ (Davison, et al., 2007), abbreviated nfatc1:NTR-mCherry; Tg(kdrl:NLS-EGFP) ${ }^{z f 109}$ 
(Blum, et al., 2008), abbreviated kdrl:GFP; Tg(flila:Cre-ERT2) ${ }^{c n 9}$ (Sánchez-Iranzo, et al., 2018), abbreviated fli la:Cre ${ }^{E R T 2} ; \mathrm{Tg}(-3.5 u b b: L O X P-L a c Z-L O X P-e G F P)^{c n 2}$ (Di Donato, et al., 2016), abbreviated Hulk; Tg(-3.5ubb:loxP-EGFP-loxP-mCherry) ${ }^{c z 1701}$ (Mosimann, et al., 2011), abbreviated $\operatorname{Tg}\left(\right.$ ubi:Switch); $\operatorname{Tg}(m y l 7: G F P)^{f 1}$ (Burns, et al., 2005), abbreviated myl7:GFP.

To generate $T g(f l i l a: H 2 B-G F P)^{b n s 319}$, abbreviated flila:H2B-GFP, a $2 \mathrm{~kb}$ fli la regulatory region was cloned upstream of $\mathrm{H} 2 \mathrm{~B}-\mathrm{GFP}$ sequence. The flila promoter sequence was amplified using the following primers: forward 5'-TTGGAGATCTCATCTTTGAC-3' and reverse 5'- GGTGGCGCTAGCTTCGCGTCTGAATTAATTCC-3'.

To generate $\operatorname{Tg}(5 x U A S-h s p 70: \operatorname{tg} f \beta 1 b-p 2 A-H 2 B-G F P)^{b n s 315}$, abbreviated UAS:tgfß1b, $\operatorname{tg} f \beta 1 b$ (XM_687246.8) was cloned downstream of the 5xUAS-hsp70 regulatory sequence. The full-length $\operatorname{tg} f \beta 1 b$ coding sequence was amplified using the following primers: forward 5'-ATGAAGGCGGAGAGTTTATT-3' and reverse 5'-

\section{CAACACTTGCAGGTTTTCAC-3'.}

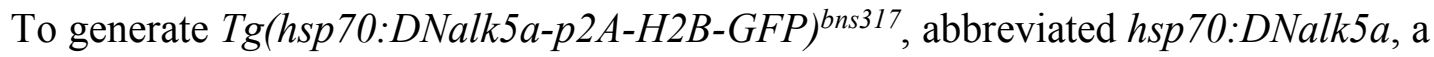
partial coding sequence of alk5a (NM_001037683.2) lacking the intracellular STK (serine-threonine kinase) domain was cloned downstream of the $h s p 70$ promoter sequence. The DNalk5a coding sequence was amplified using the following primers: forward 5' - ATGAGCTCCGCCGCGATGG-3' and reverse 5'GGTCCTGGCGATGGTCCGTT-3'.

All vectors had Tol2 elements to facilitate genome integration.

\section{Luciferase assay and plasmids}

For the luciferase expression we generated p3TP:Luc2, SV40:hRLuc2 plasmid from the pG14.14 GLO backbone (Promega), by inserting the promoter from p3TP-Lux (Addgene) upstream of the luciferase (Luc2) and the human Renilla luciferase coding sequence (amplified from pG14.79, Promega) to serve as an internal control. The 3TP promoter sequence was amplified using the following primers: forward 5'CAGCTGAAGCTCCCTTCCAG-3' and reverse 5'-GGTACCCCGACACGGCAC-3'. The Luc2 sequence was amplified using the following primers: forward 5'GGTGTGGAAAGTCCCCAGGC-3' and reverse 5'-CACACAAAAAACCAACACAC3 '.

As a negative control we used the pCS2+ plasmid.

For the expression of human Alk5 dominant negative we used the previously established plasmid pCMV5B-TGFß receptor I K232R (Addgene) (Wieser, et al., 1995).

For the expression of zebrafish Alk5a, to define the baseline activation with the zebrafish protein in the human cells and TGF 3 ligand, we generated the pCMV:alk5a plasmid by inserting the alk5a coding sequence (NM_001037683.2) downstream of the CMV promoter in the pCMV-Tol2 plasmid (Addgene). The full-length alk5a coding sequence was amplified using the following primers: forward 5'-ATGAGCTCCGCCGCGATGG- 
3' and reverse 5'-TTATATCTTGATGCCCTCTT-3'. For the validation of the zebrafish dominant negative Alk5a we generated the pCMV:DNalk5a-linker-GFP plasmid by cloning the truncated sequence of alk5a coding sequence downstream of the CMV promoter (Addgene), followed by a flexible linker and the GFP coding sequence. The DNalk5a coding sequence was amplified with the primers mentioned in the previous section. The Flexible linker +5 'GFP sequence was amplified using the following primers: forward 5'-

CTTGGACCTGGACTCGGATCCGGAGTGAGCAAGGGCGAGGAGCT-3’ and reverse 5'-TTACTTGTACAGCTCGTCCA-3'.

HEK-293T cells, plated in a 24-well plate, were transfected with $300 \mathrm{ng} / \mathrm{well}$ p3TP:Luc2, SV40:hRLuc2 and $300 \mathrm{ng} /$ well of another construct according to the well and $1.5 \mu \mathrm{l} /$ well Lipofectamine 2000 Transfection Reagent (Thermo Fisher Scientific), for 5-6 hours, in 1xDMEM+Glutamax (Thermo Fisher Scientific) containing 10\% FBS Superior (Biochrom) without antibiotic. Plasmids used are described above. The medium was then changed to $1 \mathrm{xDMEM}+$ Glutamax with $10 \%$ FBS and 1\% Penicillin-Streptomycin (PenStrep, Sigma) and the cells were cultured over-night.

The next morning, the media were replaced with fresh serum-free media (with $1 \%$ PenStrep) containing $2 \mathrm{ng} / \mathrm{ul}$ TGF $\beta 1$ ligand (from a $10 \mu \mathrm{g} / \mathrm{ml}$ stock), or no addition. After 24 hours, cells were rinsed in PBS and lysed with PLB Buffer for Luciferase Assay (Promega). The cell lysates' supernatant was used to perform the luciferase assay, using the Dual-Luciferase ${ }^{\circledR}$ Reporter Assay System (Promega), following manufacturer's instructions.

Each experiment was carried out in duplicate (two wells per condition) in at least two independent experiments.

\section{Ablation, drug treatments and heat-shock}

Cellular ablation was induced with a 6-hour treatment in Mtz solution. Briefly, Mtz (Sigma) was eluted in DMSO to a concentration of $2.5 \mathrm{M}$ immediately before treatment, and then diluted to a final concentration of $2.5 \mathrm{mM}$ in fish system water. Fish were treated in individual containers and were kept in the dark during treatment to prevent degradation of Mtz. After exposure to Mtz, water was changed twice to remove any traces of drug and fish were kept in an incubator at $28^{\circ} \mathrm{C}$ until sacrifice or $7 \mathrm{dpab}$, when they were transferred to the system.

Treatment with the TGFß inhibitor SB431542 (Calbiochem) was adapted from previous reports (Jazwinska, et al., 2007; Chablais and Jazwinska, 2012). The compound was eluted in DMSO to a concentration of $15 \mathrm{mM}$ and diluted in fish water to a final concentration of $15 \mu \mathrm{M}$. Fish were treated with the drug solution during the 24 hours prior to Mtz treatment and from 24 to $48 \mathrm{hpab}$. 
To perform EdU incorporation, each animal was injected intraperitoneally with $20 \mu \mathrm{l}$ of $10 \mathrm{mM}$ EdU (Thermo Fisher) solution 3 hours prior organ collection. The stock solution was prepared in DMSO to a concentration of $1 \mathrm{M}$ and diluted in PBS prior injection. Injections were performed using 29G U-100 insulin syringes (BD Micro-Fine).

$\mathrm{Cre}^{\text {ERT2}}$-based cell recombination was induced with intraperitoneal injection of $15 \mu \mathrm{l}$ of 1.25 mM 4-hydroxytamoxifen (Sigma) diluted in PBS from a stock solution of $25 \mathrm{mM}$ eluted in ethanol (Kikuchi, et al., 2010). Prior dilution, stock solution was heated at $65^{\circ} \mathrm{C}$ for 5 minutes, to ensure the complete dissolution of the reagent. Animals were injected for three consecutive days and let to recover in isolated recipients for two days prior cell ablation.

For heat-shock treatments, fish were placed in pre-heated water at $33^{\circ} \mathrm{C}$ for a period of 1 hour at $20 \mathrm{hpab}$ and transferred to an individual container with system water at $28^{\circ} \mathrm{C}$.

\section{Cell transplants}

For efficient engraftment of GFP+ WKM donor cells the host hematopoietic tissue must be ablated (Traver, et al., 2004). Therefore, $T g$ (nfatc 1:NTR-mCherry) hosts were irradiated prior WKM transplantation. Fish were placed in petri dishes and irradiated with a single 15 Gy dose in a RS-2000 X-Ray irradiator (Rad Source) the two days before WKM transplant. WKMs were dissected from $\operatorname{Tg}$ (ubi:switch); $\operatorname{Tg}$ (nfatc1:NTR-mCherry) fish, placed in cold PBS + FBS 5\%, and dissociated with a pipette. Cells were filtered through a $70 \mu \mathrm{m}$ cell strainer (Corning) and centrifuged for 8 minutes at $300 \mathrm{x}$. They were resuspended in $30 \mu \mathrm{l}$ of $1 \mathrm{x}$ PBS per kidney and any trace of FBS was removed. A volume of $10 \mu \mathrm{l}$ of cell suspension was injected intraperitoneally in each host. Injected animals were kept in the incubator for 7 days in clean water in individual containers to allow recovery and then transferred to the system. One month post transplantation, after reconstitution of the host kidney marrow, incorporation of the donor cells was confirmed by detection of GFP+ cells and the fish were subjected to valve cell ablation protocol as described above.

\section{Doppler Echocardiography}

Zebrafish were anesthetized using $0.016 \%$ buffered Tricaine diluted in system water. Animals were placed in supine position in a bed made of modelling clay, adjustable to the size of the fish. Fish were fully submerged in anesthesia solution to ensure propagation of the ultrasound signal. Vevo2100® Imaging System (VisualSonics) and VisualSonics Ultrasound Imaging Software (Version 1.6.0) were used for echocardiography together with the high frequency MicroScan transducer (MS700 v3.0) at a frequency of $40 \mathrm{MHz}$. Transducer head was oriented along the longitudinal axis of the fish and image was acquired with anterior side to the left and posterior side to the right. The imaging was 
performed in Color Doppler mode. To account for variations, videos were recorded for 10 seconds and across different $2 \mathrm{D}$ planes spanning the AV canal. Image acquisition was completed within 5 minutes of sedation to avoid cardiac function aberrations. After imaging, the fish were returned to a container containing system water and observed until recovery. Vevo Lab ${ }^{\mathrm{TM}}$ software package v.1.7.0 (VisualSonics) was used for image analysis.

\section{Transmitted Electron Microscopy}

Zebrafish hearts were dissected and fixed in 4\% paraformaldehyde with $2.5 \%$ glutaraldehyde in $0.05 \mathrm{M}$ HEPES buffer ( $\mathrm{pH}$ 7.2) for 2 hours at room temperature, and subsequently stored at $4^{\circ} \mathrm{C}$. To facilitate the orientation of the samples, hearts were preembedded in 3\% LMP-Agarose. Samples were rinsed three times in 0.05 M HEPES buffer ( $\mathrm{pH} 7.2)$ and post-fixed in $1 \%(\mathrm{w} / \mathrm{v}) \mathrm{OsO}_{4}$ for 1 hour. After washing three times with distilled water, blocs were stained with $2 \%$ uranyl acetate for 1 hour. Samples were dehydrated through a graded series of ethanol washes, transferred to propylene oxide and embedded in Epon according to standard procedures (Laue, 2010). Tissue semi-thin sections (900 nm thick) were obtained in a Ultracut E microtome (Reichert-Jung, Leica) and stained with Richardson staining solution (Richardson, et al., 1960). Ultra-thin 70 $\mathrm{nm}$ sections were then collected on copper $2 \times 1$ slot grids. Sections were examined with a JEM-1400 Plus transmission electron microscope (Jeol, Japan), operated at an accelerating voltage of $120 \mathrm{kV}$. Digital images were recorded with an EM-14800Ruby Digital CCD camera unit.

\section{Histology and Imaging}

Hearts were fixed in 4\% buffered paraformaldehyde for 1 hour at room-temperature, washed in 1x PBS and embedded as previously described (Mateus, et al., 2015). Briefly, the tissue was placed overnight at $4{ }^{\circ} \mathrm{C}$ in a solution of $30 \%(\mathrm{w} / \mathrm{v})$ sucrose prepared in $1 \mathrm{x}$ PBS, pre-embedded in $7.5 \%(\mathrm{w} / \mathrm{v})$ porcine gelatin (Sigma) $/ 15 \%(\mathrm{w} / \mathrm{v})$ sucrose in $1 \mathrm{x}$ PBS at $37^{\circ} \mathrm{C}$ for 1 hour and embedded with a new solution of gelatin. Tissue blocks were frozen in isopentane (Sigma) cooled in liquid nitrogen. Cryosections were cut at $10 \mu \mathrm{m}$ using a Leica CM3050S cryostat (Leica) and were kept at $-20^{\circ} \mathrm{C}$ until further use. When preparing samples for in situ hybridization, all solutions and materials were kept RNasefree and slides were stored at $-80^{\circ} \mathrm{C}$.

Prior further analyses, slides were thawed for 10 minutes at room temperature and gelatin was removed in $1 \mathrm{x} \mathrm{PBS}$ at $37^{\circ} \mathrm{C}$. Immunodetection started with a wash in $0.1 \mathrm{M}$ glycine (Sigma) followed by permeabilization for 7 minutes at $-20^{\circ} \mathrm{C}$ in pre-cooled acetone. 
Sections were incubated in a blocking solution of PBDX (1\% (w/v) Bovine Serum Albumin, $1 \%(\mathrm{v} / \mathrm{v})$ DMSO, $1 \%(\mathrm{v} / \mathrm{v})$ Triton-X100 in PBS) with 15\% (v/v) goat serum for a minimum of two hours at room temperature. Incubation with the following primary antibody was performed overnight at $4^{\circ} \mathrm{C}$ : GFP $(1: 200)$, mCherry $(1: 100)$, Elastin 1 (1:100), Biotinylated-HABP (1:100), Fli1 (1:100), L-Plastin (1:200), pSmad3 (1:100). Slides were washed several times with PBDX and incubated with the corresponding Alexa Fluor conjugated secondary antibodies (1:500) overnight at $4^{\circ} \mathrm{C}$. For all incubations, slides were covered with a piece of Parafilm-M to ensure homogenous distribution of the solution. Slides were washed a minimum of 3 times for 15 minutes each in a solution of $0.3 \%(\mathrm{v} / \mathrm{v})$ Triton-X100 in PBS (PBST) and counterstained with $0.0002 \%$ (w/v) DAPI (Merck) in PBST for 10 minutes. Slides were then washed a minimum of 3 times for 15 minutes each in PBST and mounted with DAKO Fluorescence mounting medium.

Elastin1 antibody was purified from the previously described serum stock (Miao, et al., 2007). pSmad 3 and Flil detection required an antigen retrieval step in 10mM Sodium citrate buffer $\mathrm{pH} 6.0$ with $0.05 \%(\mathrm{v} / \mathrm{v})$ Tween for 10 minutes at $95^{\circ} \mathrm{C}$. HABP detection was adapted from a previous report (Govindan and Iovine, 2014) and included an additional step in methanol for 10 minutes at room temperature before the glycine.

For EdU detection, we followed the Click-iT EdU Cell Proliferation Kit for Imaging, Alexa Fluor 647 dye protocol (Thermo Fisher) and incubated each slide with $100 \mu$ of Click-iT reaction solution for 30 minutes at room temperature prior incubation with antibodies.

For TUNEL detection, we followed the instructions from the In situ Cell Death Detection Kit, Fluorescein (Roche). We added a step in methanol for 10 minutes before the glycine and incubated each slide with $50 \mu \mathrm{l}$ of TUNEL solution at $37^{\circ} \mathrm{C}$ for 1 hour, after incubation with secondary antibody.

In situ hybridization was performed following the RNAscope Fluorescent Assay (Advanced Cell Diagnosis) protocol for frozen tissue. We used a custom made tgf $\beta 1 b$ probe (Advanced Cell Diagnosis) and, when required, prior DAPI staining, we started the immunodetection protocol from the blocking solution step as described above.

All sections were imaged using a Zeiss LSM800 (Zeiss) inverted microscope, and ZEN 2.3 (Blue edition).

\section{Data analyses and quantification}

Image analyses and quantifications were performed using the FiJi ImageJ softawre (Schindelin, et al., 2012).

All quantifications represent an average of 3-5 serial mid-luminal sections per individual. 
Percentage of surviving cells was quantified by dividing the number of DAPI + nfatc $1+$ cells inside the AV valve leaflets after ablation with an average $(n=4)$ of the total number of $n$ fatcl $1+$ cells in uninjured AV valves. TUNEL+ cells represent the percentage of apopototic cells over the total number of DAPI $+n f a t c 1+$ in that specific time point. The ratio El1/HABP was calculated from the Elastin1 and HABP total areas. pSmad3 + cells were counted in the AV canal region, excluding epicardium, myocardium and non luminal endocardium.

All statistical analyses were performed in GraphPad Prism (Version 6.07) and illustrations were done in Inkscape (XQuartz X11).

\section{Laser Capture Microdissection}

Hearts from uninjured, $48 \mathrm{hpab}$ and $21 \mathrm{dpab}$ animals were directly embedded in TissueTek O.C.T. compound (VWR) without tissue fixation and were kept at $-80^{\circ} \mathrm{C}$ until further use.

Cryosections with a thickness of $10 \mu \mathrm{m}$ were placed on membrane coated glass slides (Leica) and were prevented from thawing until microdissection. Sections were rapidly dehydrated and briefly stained with Mayer's hematoxylin and Bluing reagent (Scott's tap water) for $15 \mathrm{sec}$ followed by washes in increasing gradient of 70 to $100 \%$ ethanol. AV valves and surrounding tissues were microdissected under optical control using the Laser microdissection device LMD6000 (Leica). The microdissected material was captured in Eppendorf tubes filled with $50 \mu$ l RNA lysis buffer (RLT $+\beta$-mercaptoethanol). We collected 3 biological replicates per time point, comprising a pool of 50-105 sections from 2 hearts per each replicate. After sample collection, the dissected material was preserved at $-80^{\circ} \mathrm{C}$ until isolation of the RNA.

\section{Transcriptome analysis}

For RNA-seq, RNA was isolated from the laser microdissected samples using the miRNeasy micro Kit (Qiagen) combined with on-column DNase digestion (DNase-Free DNase Set, Qiagen) to avoid contamination by genomic DNA. RNA and library preparation integrity were verified with a BioAnalyzer 2100 (Agilent) or LabChip Gx Touch 24 (Perkin Elmer). 20 ng of total RNA was used as input for PolyA enrichment (NEXTflexTM PolyA Beads) followed by library preparation using NEXTflexTM Rapid Directional qRNA-SeqTM Kit (Bioo Scientific Corp). Sequencing was performed on the NextSeq500 instrument (Illumina) using v2 chemistry, resulting in average of $38 \mathrm{M}$ reads per library with $1 \times 75 b$ single end setup. Raw reads were assessed for quality, adapter content and duplication rates with FastQC (Andrews S. 2010, FastQC: a quality control tool for high throughput sequence data. Available online at: 
http://www.bioinformatics.babraham.ac.uk/projects/fastqc). Trimmomatic version 0.33 was employed to trim reads after a quality drop below a mean of Q15 in a window of 5 nucleotides (Davis, et al., 2013). Only reads of at least 15 nucleotides were cleared for subsequent analyses. Trimmed and filtered reads were aligned versus the Ensembl zebrafish genome version danRer11 (GRCz11) using STAR 2.6.0c with the parameters "-outFilterMismatchNoverLmax 0.1 --alignIntronMax 200000” (Dobin, et al., 2013). The number of reads aligning to genes was counted with featureCounts 1.6 .0 from the Subread package (Liao, et al., 2014). Only reads mapping at least partially inside exons were admitted and aggregated per gene. Reads overlapping multiple genes or aligning to multiple regions were excluded. Differentially expressed genes were identified using DESeq2 version 1.18.1 (Love, et al., 2014). Genes were classified to be significantly differentially expressed (DEG) with Benjamini-Hochberg corrected P-Value $<0.05$ and $0.59 \leq \log 2 \mathrm{FC} \geq+0.59$. The Ensemble annotation was enriched with UniProt data (release 12.04.2018) based on Ensembl gene identifiers (Activities at the Universal Protein Resource (UniProt)).

MA plots were produced to show DEG regulation per contrast based on DESeq2 normalized counts. Dimension reduction analyses (PCA) were performed on DESeq2 normalized and regularized log transformed counts using the $\mathrm{R}$ packages FactoMineR and factoextra. For the assembly of the heatmap, DESeq normalized counts of all DEGs were transformed to a Z-score per row and clustered using k-means clustering (four clusters). Genes of each cluster were subjected to gene set enrichment analysis using KOBAS (Xie, et al., 2011). Main overrepresented pathways per cluster were identified and agglomerated based on manual inspection of significant Reactome database gene sets with P-Value $<=0.05$.

\section{Quantitative PCR}

For qPCR analyses single hearts were homogenized with the Bullet Blender Gold (Next Advance). Total RNA was isolated using the RNeasy Mini Kit (Qiagen) followed by DNAse digestion (Invitrogen). cDNA was synthesized using the High Capacity RNA-tocDNA kit (Applied Byosystems) and qPCR was performed in a BIO-RAD CFX Connect Real-Time System with the DyNAmo Color Flash SYBR Green Master Mix (Thermo Scientific). 


\section{References}

Anderton, M.J., Mellor, H.R., Bell, A., Sadler, C., Pass, M., Powell, S., Steele, S.J., Roberts, R.R., and Heier, A. (2011). Induction of heart valve lesions by smallmolecule ALK5 inhibitors. Toxicol. Pathol. 39, 916-24.

Anstine, L.J., Bobba, C., Ghadiali, S., and Lincoln, J. (2016). Growth and maturation of heart valves leads to changes in endothelial cell distribution, impaired function, decreased metabolism and reduced cell proliferation. J. Mol. Cell. Cardiol. 100, 7282 .

Baldwin, A.C.W., and Tolis, G., Jr. (2019). Tissue valve degeneration and mechanical valve failure. Curr. Treat. Options Cardiovasc. Med. 21, 33.

Beis, D., Bartman, T., Jin, S.W., Scott, I.C., D'Amico, L.A., Ober, E.A., Verkade, H., Frantsve, J., Field, H.A., Wehman, A., et al. (2005). Genetic and cellular analyses of zebrafish atrioventricular cushion and valve development. Development 132, 4193-204.

Benton, J.A., DeForest, C.A., Vivekanandan, V., and Anseth, K.S. (2009). Photocrosslinking of gelatin macromers to synthesize porous hydrogels that promote valvular interstitial cell function. Tissue Eng. Part A 15, 3221-3230.

Blum, Y., Belting, H.G., Ellertsdottir, E., Herwig, L., Luders, F., and Affolter, M. (2008). Complex cell rearrangements during intersegmental vessel sprouting and vessel fusion in the zebrafish embryo. Dev. Biol. 316, 312-22.

Boselli, F., and Vermot, J. (2016). Live imaging and modeling for shear stress quantification in the embryonic zebrafish heart. Methods 94, 129-34.

Bouten, C.V.C., Driessen-Mol, A., and Baaijens, F.P.T. (2012). In situ heart valve tissue engineering: simple devices, smart materials, complex knowledge. Expert Rev. Med. Devices 9, 453-455.

Bouten, C.V.C., Smits, A., and Baaijens, F.P.T. (2018). Can we grow valves inside the heart? Perspective on material-based in situ heart valve tissue engineering. Front. Cardiovasc. Med. 5, 54.

Burns, C.G., Milan, D.J., Grande, E.J., Rottbauer, W., MacRae, C.A., and Fishman, M.C. (2005). High-throughput assay for small molecules that modulate zebrafish embryonic heart rate. Nat. Chem. Biol. 1, 263-4.

Cadart, C., Zlotek-Zlotkiewicz, E., Le Berre, M., Piel, M., and Matthews, H.K. (2014). Exploring the function of cell shape and size during mitosis. Dev. Cell 29, 159-69.

Chablais, F., and Jazwinska, A. (2012). The regenerative capacity of the zebrafish heart is dependent on TGFß signaling. Development 139, 1921-30. 
Cheung, D.Y., Duan, B., and Butcher, J.T. (2015). Current progress in tissue engineering of heart valves: multiscale problems, multiscale solutions. Expert Opin. Biol. Ther. $15,1155-72$.

Conway, S.J., Doetschman, T., and Azhar, M. (2011). The inter-relationship of periostin, TGFß, and BMP in heart valve development and valvular heart diseases.

ScientificWorldJournal 11, 1509-24.

Curado, S., Anderson, R.M., Jungblut, B., Mumm, J., Schroeter, E., and Stainier, D.Y. (2007). Conditional targeted cell ablation in zebrafish: a new tool for regeneration studies. Dev. Dyn. 236, 1025-35.

Datta, S., Malhotra, L., Dickerson, R., Chaffee, S., Sen, C.K., and Roy, S. (2015). Laser capture microdissection: Big data from small samples. Histol. Histopathol. 30, 1255-69.

David, T.E. (2016). Aortic valve replacement in children and young adults. J. Am. Coll. Cardiol. 67, 2871-3.

Davis, M.P., van Dongen, S., Abreu-Goodger, C., Bartonicek, N., and Enright, A.J. (2013). Kraken: a set of tools for quality control and analysis of high-throughput sequence data. Methods 63, 41-9.

Davison, J.M., Akitake, C.M., Goll, M.G., Rhee, J.M., Gosse, N., Baier, H., Halpern, M.E., Leach, S.D., and Parsons, M.J. (2007). Transactivation from Gal4-VP16 transgenic insertions for tissue-specific cell labeling and ablation in zebrafish. Dev. Biol. 304, 811-24.

de la Pompa, J.L., and Epstein, J.A. (2012). Coordinating tissue interactions: Notch signaling in cardiac development and disease. Dev. Cell 22, 244-54.

De Visscher, G., Lebacq, A., Mesure, L., Blockx, H., Vranken, I., Plusquin, R., Meuris, B., Herregods, M.-C., Van Oosterwyck, H., and Flameng, W. (2010). The remodeling of cardiovascular bioprostheses under influence of stem cell homing signal pathways. Biomaterials 31, 20-28.

Deng, C., Dong, N., Shi, J., Chen, S., Xu, L., Shi, F., Hu, X., and Zhang, X. (2011). Application of decellularized scaffold combined with loaded nanoparticles for heart valve tissue engineering in vitro. J. Huazhong Univ. Sci. Technolog. Med. Sci. 31, 88-93.

Derynck, R., and Budi, E.H. (2019). Specificity, versatility, and control of TGF- $ß$ family signaling. Sci. Signal. 12, eaav5183.

Di Donato, V., De Santis, F., Auer, T.O., Testa, N., Sanchez-Iranzo, H., Mercader, N., Concordet, J.P., and Del Bene, F. (2016). 2C-Cas9: a versatile tool for clonal analysis of gene function. Genome Res. 26, 681-92. 
Dobin, A., Davis, C.A., Schlesinger, F., Drenkow, J., Zaleski, C., Jha, S., Batut, P., Chaisson, M., and Gingeras, T.R. (2013). STAR: ultrafast universal RNA-seq aligner. Bioinformatics 29, 15-21.

Dohmen, P.M., da Costa, F., Yoshi, S., Lopes, S.V., da Souza, F.P., Vilani, R., Wouk, A.F., da Costa, M., and Konertz, W. (2006). Histological evaluation of tissueengineered heart valves implanted in the juvenile sheep model: is there a need for in-vitro seeding? J. Heart Valve Dis. 15, 823-829.

Driessen-Mol, A., Emmert, M.Y., Dijkman, P.E., Frese, L., Sanders, B., Weber, B., Cesarovic, N., Sidler, M., Leenders, J., Jenni, R., et al. (2014). Transcatheter implantation of homologous "off-the-shelf" tissue-engineered heart valves with self-repair capacity: long-term functionality and rapid in vivo remodeling in sheep. J. Am. Coll. Cardiol. 63, 1320-1329.

Dutta, P., and Lincoln, J. (2018). Calcific Aortic Valve Disease: a Developmental Biology Perspective. Curr. Cardiol. Rep. 20, 21.

Emmert, M.Y., Schmitt, B.A., Loerakker, S., Sanders, B., Spriestersbach, H., Fioretta, E.S., Bruder, L., Brakmann, K., Motta, S.E., Lintas, V., et al. (2018).

Computational modeling guides tissue-engineered heart valve design for long-term in vivo performance in a translational sheep model. Sci. Transl. Med. 10, eaan4587.

Fallahiarezoudar, E., Ahmadipourroudposht, M., Idris, A., and Mohd Yusof, N. (2015). A review of: application of synthetic scaffold in tissue engineering heart valves. Mater. Sci. Eng. C. Mater. Biol. Appl. 48, 556-65.

Gemberling, M., Bailey, T.J., Hyde, D.R., and Poss, K.D. (2013). The zebrafish as a model for complex tissue regeneration. Trends Genet. 29, 611-20.

Goecke, T., Theodoridis, K., Tudorache, I., Ciubotaru, A., Cebotari, S., Ramm, R., Hoffler, K., Sarikouch, S., Vasquez Rivera, A., Haverich, A., et al. (2018). In vivo performance of freeze-dried decellularized pulmonary heart valve allo- and xenografts orthotopically implanted into juvenile sheep. Acta Biomater. 68, 41-52.

Govindan, J., and Iovine, M.K. (2014). Hapln1a is required for connexin43-dependent growth and patterning in the regenerating fin skeleton. PLoS One 9, e88574.

Gunawan, F., Gentile, A., Fukuda, R., Tsedeke, A.T., Jimenez-Amilburu, V., Ramadass, R., Iida, A., Sehara-Fujisawa, A., and Stainier, D.Y.R. (2019). Focal adhesions are essential to drive zebrafish heart valve morphogenesis. J. Cell Biol. 218, 10391054.

Harrington, J.K., Chahboune, H., Criscione, J.M., Li, A.Y., Hibino, N., Yi, T., Villalona, G.A., Kobsa, S., Meijas, D., Duncan, D.R., et al. (2011). Determining the fate of seeded cells in venous tissue-engineered vascular grafts using serial MRI. FASEB J. 25, 4150-4161. 
Hu, N., Yost, H.J., and Clark, E.B. (2001). Cardiac morphology and blood pressure in the adult zebrafish. Anat. Rec. 264, 1-12.

Hufnagel, C.A., Harvey, P., Rabil, P.J., and McDermott, T.F. (1954). Surgical correction of aortic insufficiency. Surgery 35, 673-693.

Ibrahim, D.M., Kakarougkas, A., and Allam, N.K. (2017). Recent advances on electrospun scaffolds as matrices for tissue-engineered heart valves. Mater. Today Chem. 5, 11-23.

Iung, B. (2003). A prospective survey of patients with valvular heart disease in Europe: The Euro Heart Survey on Valvular Heart Disease. Eur. Heart J. 24, 1231-1243.

Jain, R., Engleka, K.A., Rentschler, S.L., Manderfield, L.J., Li, L., Yuan, L., and Epstein, J.A. (2011). Cardiac neural crest orchestrates remodeling and functional maturation of mouse semilunar valves. J. Clin. Invest. 121, 422-30.

James, I.A., Yi, T., Tara, S., Best, C.A., Stuber, A.J., Shah, K.V., Austin, B.F., Sugiura, T., Lee, Y.U., Lincoln, J., et al. (2015). Hemodynamic Characterization of a Mouse Model for Investigating the Cellular and Molecular Mechanisms of Neotissue Formation in Tissue-Engineered Heart Valves. Tissue Eng. Part C 21, 987-94.

Jana, S., Simari, R.D., Spoon, D.B., and Lerman, A. (2014). Drug delivery in aortic valve tissue engineering. J. Controlled Release 196, 307-23.

Jazwinska, A., Badakov, R., and Keating, M.T. (2007). Activin-ßA signaling is required for zebrafish fin regeneration. Curr. Biol. 17, 1390-5.

Jordan, J.E., Williams, J.K., Lee, S.J., Raghavan, D., Atala, A., and Yoo, J.J. (2012). Bioengineered self-seeding heart valves. J. Thorac. Cardiovasc. Surg. 143, 201-8.

Kalogirou, S., Malissovas, N., Moro, E., Argenton, F., Stainier, D.Y., and Beis, D. (2014). Intracardiac flow dynamics regulate atrioventricular valve morphogenesis. Cardiovasc. Res. 104, 49-60.

Kennamer, A., Sierad, L., Pascal, R., Rierson, N., Albers, C., Harpa, M., Cotoi, O., Harceaga, L., Olah, P., Terezia, P., et al. (2016). Bioreactor conditioning of valve scaffolds seeded internally with adult stem cells. Tissue Eng. Regen. Med. 13, 507515.

Kheradvar, A., Zareian, R., Kawauchi, S., Goodwin, R.L., and Rugonyi, S. (2017). Animal Models for Heart Valve Research and Development. Drug Discov. Today Dis. Models 24, 55-62.

Kikuchi, K., Holdway, J.E., Werdich, A.A., Anderson, R.M., Fang, Y., Egnaczyk, G.F., Evans, T., Macrae, C.A., Stainier, D.Y., and Poss, K.D. (2010). Primary contribution to zebrafish heart regeneration by gata4+ cardiomyocytes. Nature 464, $601-5$. 
Kluin, J., Talacua, H., Smits, A.I., Emmert, M.Y., Brugmans, M.C., Fioretta, E.S., Dijkman, P.E., Sontjens, S.H., Duijvelshoff, R., Dekker, S., et al. (2017). In situ heart valve tissue engineering using a bioresorbable elastomeric implant - From material design to 12 months follow-up in sheep. Biomaterials 125, 101-117.

Kruithof, B.P., Duim, S.N., Moerkamp, A.T., and Goumans, M.J. (2012). TGFß and BMP signaling in cardiac cushion formation: Lessons from mice and chicken. Differentiation 84, 89-102.

Laue, M. (2010). Electron Microscopy of Viruses. In Methods Cell Biol., MüllerReichert, T., ed. (Cambridge, MA, USA: Academic Press), pp. 1-20.

Li, C., and Gotlieb, A.I. (2011). Transforming growth factor- $\beta$ regulates the growth of valve interstitial cells in vitro. Am. J. Pathol. 179, 1746-55.

Liao, Y., Smyth, G.K., and Shi, W. (2014). featureCounts: an efficient general purpose program for assigning sequence reads to genomic features. Bioinformatics 30, 923 30 .

Liu, A.C., and Gotlieb, A.I. (2008). Transforming growth factor- $\beta$ regulates in vitro heart valve repair by activated valve interstitial cells. Am. J. Pathol. 173, 1275-85.

Liu, K., Yu, W., Tang, M., Tang, J., Liu, X., Liu, Q., Li, Y., He, L., Zhang, L., Evans, S.M., et al. (2018). A dual genetic tracing system identifies diverse and dynamic origins of cardiac valve mesenchyme. Development 145.

Love, M.I., Huber, W., and Anders, S. (2014). Moderated estimation of fold change and dispersion for RNA-seq data with DESeq2. Genome Biol. 15, 550.

MacGrogan, D., Luxan, G., Driessen-Mol, A., Bouten, C., Baaijens, F., and de la Pompa, J.L. (2014). How to make a heart valve: from embryonic development to bioengineering of living valve substitutes. Cold Spring Harb. Perspect. Med. 4, a013912.

Martin, R.T., and Bartman, T. (2009). Analysis of heart valve development in larval zebrafish. Dev. Dyn. 238, 1796-802.

Mateus, R., Lourenco, R., Fang, Y., Brito, G., Farinho, A., Valerio, F., and Jacinto, A. (2015). Control of tissue growth by Yap relies on cell density and F-actin in zebrafish fin regeneration. Development 142, 2752-63.

Mercado-Pimentel, M.E., and Runyan, R.B. (2007). Multiple transforming growth factor$\beta$ isoforms and receptors function during epithelial-mesenchymal cell transformation in the embryonic heart. Cells Tissues Organs 185, 146-56.

Miao, M., Bruce, A.E., Bhanji, T., Davis, E.C., and Keeley, F.W. (2007). Differential expression of two tropoelastin genes in zebrafish. Matrix Biol. 26, 115-24. 
Mosimann, C., Kaufman, C.K., Li, P., Pugach, E.K., Tamplin, O.J., and Zon, L.I. (2011). Ubiquitous transgene expression and Cre-based recombination driven by the ubiquitin promoter in zebrafish. Development 138, 169-77.

Motta, S.E., Lintas, V., Fioretta, E.S., Dijkman, P.E., Putti, M., Caliskan, E., Rodriguez Cetina Biefer, H., Lipiski, M., Sauer, M., Cesarovic, N., et al. (2019). Human cellderived tissue-engineered heart valve with integrated Valsalva sinuses: towards native-like transcatheter pulmonary valve replacements. npj Regen. Med. 4, 14.

Nauroy, P., Hughes, S., Naba, A., and Ruggiero, F. (2018). The in-silico zebrafish matrisome: A new tool to study extracellular matrix gene and protein functions. Matrix Biol. 65, 5-13.

Neuenschwander, S., and Hoerstrup, S.P. (2004). Heart valve tissue engineering. Transplant Immunol. 12, 359-65.

Nkomo, V.T., Gardin, J.M., Skelton, T.N., Gottdiener, J.S., Scott, C.G., and EnriquezSarano, M. (2006). Burden of valvular heart diseases: a population-based study. The Lancet 368, 1005-1011.

Pestel, J., Ramadass, R., Gauvrit, S., Helker, C., Herzog, W., and Stainier, D.Y. (2016). Real-time 3D visualization of cellular rearrangements during cardiac valve formation. Development 143, 2217-27.

Pisharath, H., Rhee, J.M., Swanson, M.A., Leach, S.D., and Parsons, M.J. (2007). Targeted ablation of beta cells in the embryonic zebrafish pancreas using $E$. coli nitroreductase. Mech. Dev. 124, 218-29.

Poss, K.D. (2007). Getting to the heart of regeneration in zebrafish. Semin. Cell Dev. Biol. 18, 36-45.

Quinn, R.W. (2013). Animal models for bench to bedside translation of regenerative cardiac constructs. Prog. Pediatr. Cardiol. 35, 91-94.

Reimer, J., Syedain, Z., Haynie, B., Lahti, M., Berry, J., and Tranquillo, R. (2017). Implantation of a tissue-engineered tubular heart valve in growing lambs. Ann. Biomed. Eng. 45, 439-451.

Richardson, K.C., Jarett, L., and Finke, E.H. (1960). Embedding in epoxy resins for ultrathin sectioning in electron microscopy. Stain Technol. 35, 313-323.

Sánchez-Iranzo, H., Galardi-Castilla, M., Sanz-Morejón, A., González-Rosa, J.M., Costa, R., Ernst, A., Sainz de Aja, J., Langa, X., and Mercader, N. (2018). Transient fibrosis resolves via fibroblast inactivation in the regenerating zebrafish heart. Proc. Natl. Acad. Sci. U. S. A. 115, 4188-4193.

Schenke-Layland, K., Opitz, F., Gross, M., Doring, C., Halbhuber, K.J., Schirrmeister, F., Wahlers, T., and Stock, U.A. (2003). Complete dynamic repopulation of 
decellularized heart valves by application of defined physical signals-an in vitro study. Cardiovasc. Res. 60, 497-509.

Scherz, P.J., Huisken, J., Sahai-Hernandez, P., and Stainier, D.Y. (2008). High-speed imaging of developing heart valves reveals interplay of morphogenesis and function. Development 135, 1179-87.

Schindelin, J., Arganda-Carreras, I., Frise, E., Kaynig, V., Longair, M., Pietzsch, T., Preibisch, S., Rueden, C., Saalfeld, S., Schmid, B., et al. (2012). Fiji: an opensource platform for biological-image analysis. Nat. Methods 9, 676-82.

Schmidt, D., Dijkman, P.E., Driessen-Mol, A., Stenger, R., Mariani, C., Puolakka, A., Rissanen, M., Deichmann, T., Odermatt, B., Weber, B., et al. (2010). Minimallyinvasive implantation of living tissue engineered heart valves: a comprehensive approach from autologous vascular cells to stem cells. J. Am. Coll. Cardiol. 56, 510-20.

Schulz, A., Brendler, J., Blaschuk, O., Landgraf, K., Krueger, M., and Ricken, A.M. (2019). Non-pathological chondrogenic features of valve interstitial cells in normal adult zebrafish. J. Histochem. Cytochem. 67, 361-373.

Snarr, B.S., Kern, C.B., and Wessels, A. (2008). Origin and fate of cardiac mesenchyme. Dev. Dyn. 237, 2804-19.

Sotiropoulos, F., Le, T.B., and Gilmanov, A. (2016). Fluid mechanics of heart valves and their replacements. Annu. Rev. Fluid Mech. 48, 259-283.

Staudt, D., and Stainier, D. (2012). Uncovering the molecular and cellular mechanisms of heart development using the zebrafish. Annu. Rev. Genet. 46, 397-418.

Steed, E., Faggianelli, N., Roth, S., Ramspacher, C., Concordet, J.P., and Vermot, J. (2016). klf2a couples mechanotransduction and zebrafish valve morphogenesis through fibronectin synthesis. Nat. Commun. 7, 11646.

Sutherland, F.W., Perry, T.E., Yu, Y., Sherwood, M.C., Rabkin, E., Masuda, Y., Garcia, G.A., McLellan, D.L., Engelmayr, G.C., Jr., Sacks, M.S., et al. (2005). From stem cells to viable autologous semilunar heart valve. Circulation 111, 2783-91.

Théry, M., and Bornens, M. (2008). Get round and stiff for mitosis. HFSP J. 2, 65-71.

Traver, D., Paw, B.H., Poss, K.D., Penberthy, W.T., Lin, S., and Zon, L.I. (2003). Transplantation and in vivo imaging of multilineage engraftment in zebrafish bloodless mutants. Nat. Immunol. 4, 1238-46.

Traver, D., Winzeler, A., Stern, H.M., Mayhall, E.A., Langenau, D.M., Kutok, J.L., Look, A.T., and Zon, L.I. (2004). Effects of lethal irradiation in zebrafish and rescue by hematopoietic cell transplantation. Blood 104, 1298-305. 
Tsang, H.G., Rashdan, N.A., Whitelaw, C.B., Corcoran, B.M., Summers, K.M., and MacRae, V.E. (2016). Large animal models of cardiovascular disease. Cell Biochem. Funct. 34, 113-32.

Tudorache, I., Theodoridis, K., Baraki, H., Sarikouch, S., Bara, C., Meyer, T., Hoffler, K., Hartung, D., Hilfiker, A., Haverich, A., et al. (2016). Decellularized aortic allografts versus pulmonary autografts for aortic valve replacement in the growing sheep model: haemodynamic and morphological results at 20 months after implantation. Eur. J. Cardiothorac. Surg. 49, 1228-38.

van Geldorp, M.W.A., Heuvelman, H.J., Kappetein, A.P., Busschbach, J.J.V., Takkenberg, J.J.M., and Bogers, A.J.J.C. (2013). The effect of aortic valve replacement on quality of life in symptomatic patients with severe aortic stenosis. Neth. Heart J. 21, 28-35.

VeDepo, M.C., Detamore, M.S., Hopkins, R.A., and Converse, G.L. (2017). Recellularization of decellularized heart valves: Progress toward the tissueengineered heart valve. J. Tissue Eng. 8, 1-21.

Visconti, R.P., Ebihara, Y., LaRue, A.C., Fleming, P.A., McQuinn, T.C., Masuya, M., Minamiguchi, H., Markwald, R.R., Ogawa, M., and Drake, C.J. (2006). An in vivo analysis of hematopoietic stem cell potential hematopoietic origin of cardiac valve interstitial cells. Circul. Res. 98, 690-696.

Walsh, E.C., and Stainier, D.Y.R. (2001). UDP-Glucose Dehydrogenase required for cardiac valve formation in zebrafish. Science 293, 1670-1673.

Weber, B., Dijkman, P.E., Scherman, J., Sanders, B., Emmert, M.Y., Grunenfelder, J., Verbeek, R., Bracher, M., Black, M., Franz, T., et al. (2013). Off-the-shelf human decellularized tissue-engineered heart valves in a non-human primate model. Biomaterials 34, 7269-80.

Wessels, A., van den Hoff, M.J., Adamo, R.F., Phelps, A.L., Lockhart, M.M., Sauls, K., Briggs, L.E., Norris, R.A., van Wijk, B., Perez-Pomares, J.M., et al. (2012). Epicardially derived fibroblasts preferentially contribute to the parietal leaflets of the atrioventricular valves in the murine heart. Dev. Biol. 366, 111-24.

White, M.P., Theodoris, C.V., Liu, L., Collins, W.J., Blue, K.W., Lee, J.H., Meng, X., Robbins, R.C., Ivey, K.N., and Srivastava, D. (2015). NOTCH1 regulates matrix gla protein and calcification gene networks in human valve endothelium. J. Mol. Cell. Cardiol. 84, 13-23.

Wieser, R., Wrana, J.L., and Massagué, J. (1995). GS domain mutations that constitutively activate TßR-I, the downstream signaling component in the TGFß receptor complex. The EMBO Journal 14, 2199-2208. 
Wirrig, E.E., and Yutzey, K.E. (2014). Conserved transcriptional regulatory mechanisms in aortic valve development and disease. Arterioscler. Thromb. Vasc. Biol. 34, 73741.

Wissing, T.B., Bonito, V., Bouten, C.V.C., and Smits, A. (2017). Biomaterial-driven in situ cardiovascular tissue engineering - a multi-disciplinary perspective. NPJ Regen. Med. 2, 18.

Xie, C., Mao, X., Huang, J., Ding, Y., Wu, J., Dong, S., Kong, L., Gao, G., Li, C.Y., and Wei, L. (2011). KOBAS 2.0: a web server for annotation and identification of enriched pathways and diseases. Nucleic Acids Res. 39, W316-22.

Yalcin, H.C., Shekhar, A., McQuinn, T.C., and Butcher, J.T. (2011). Hemodynamic patterning of the avian atrioventricular valve. Dev. Dyn. 240, 23-35.

Yamagishi, T., Ando, K., and Nakamura, H. (2009). Roles of TGFß and BMP during valvulo-septal endocardial cushion formation. Anat. Sci. Int. 84, 77-87.

Yutzey, K.E., Demer, L.L., Body, S.C., Huggins, G.S., Towler, D.A., Giachelli, C.M., Hofmann-Bowman, M.A., Mortlock, D.P., Rogers, M.B., Sadeghi, M.M., et al. (2014). Calcific aortic valve disease: a consensus summary from the Alliance of Investigators on Calcific Aortic Valve Disease. Atertio. Thromb. Vasc. Biol. 34, 2387-93. 
Bensimon-Brito et al., Figure 1

A
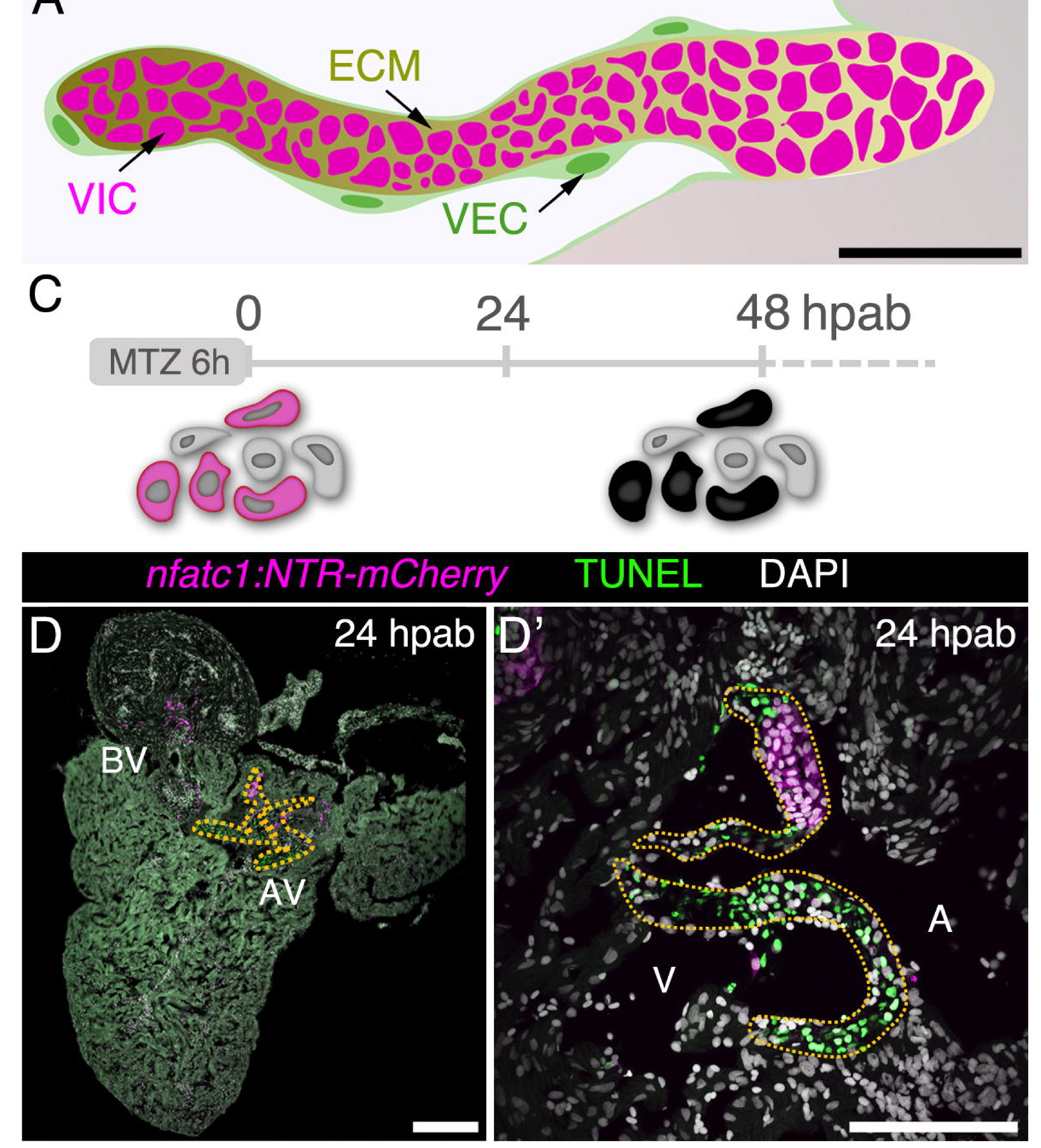

E

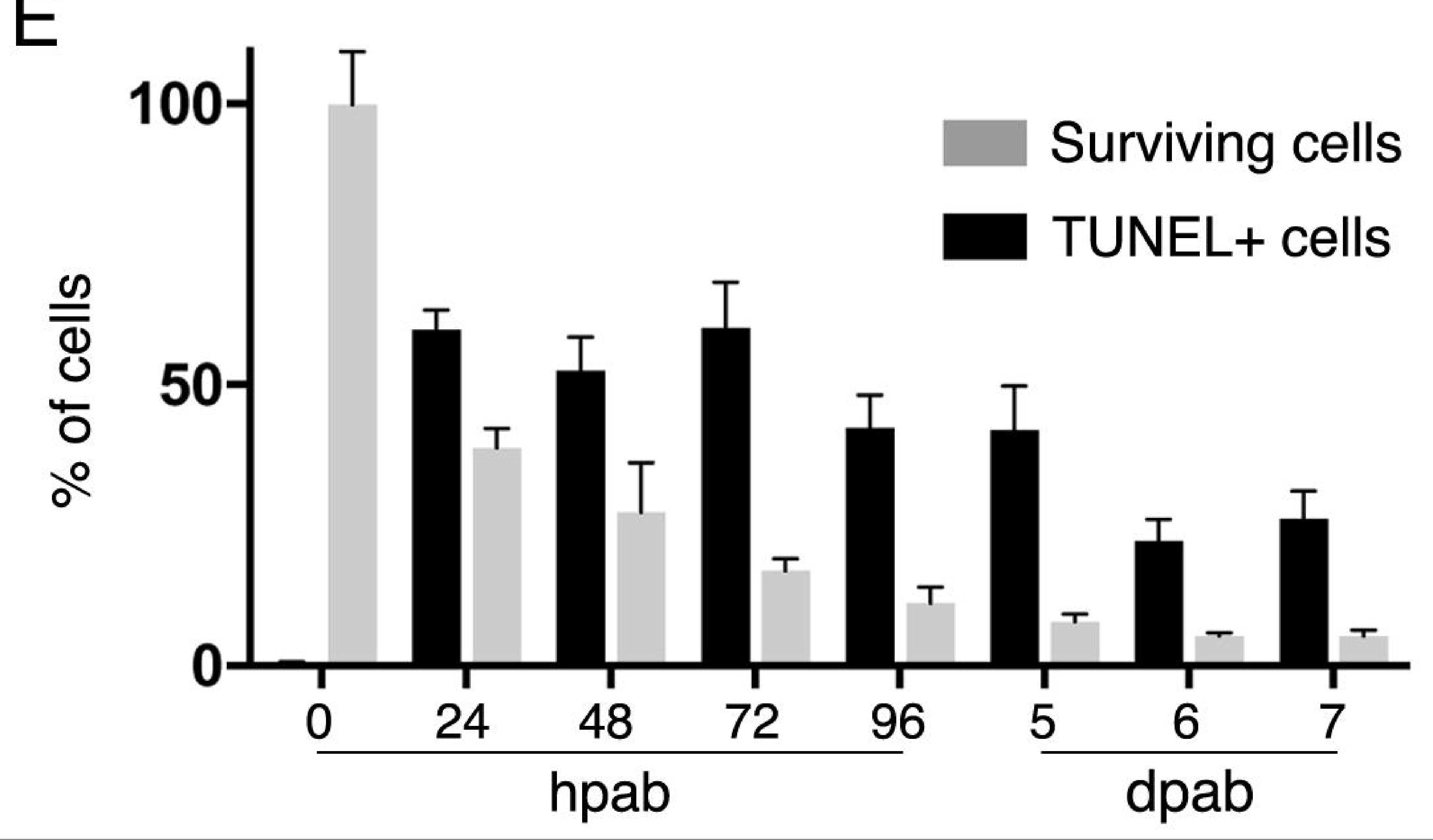

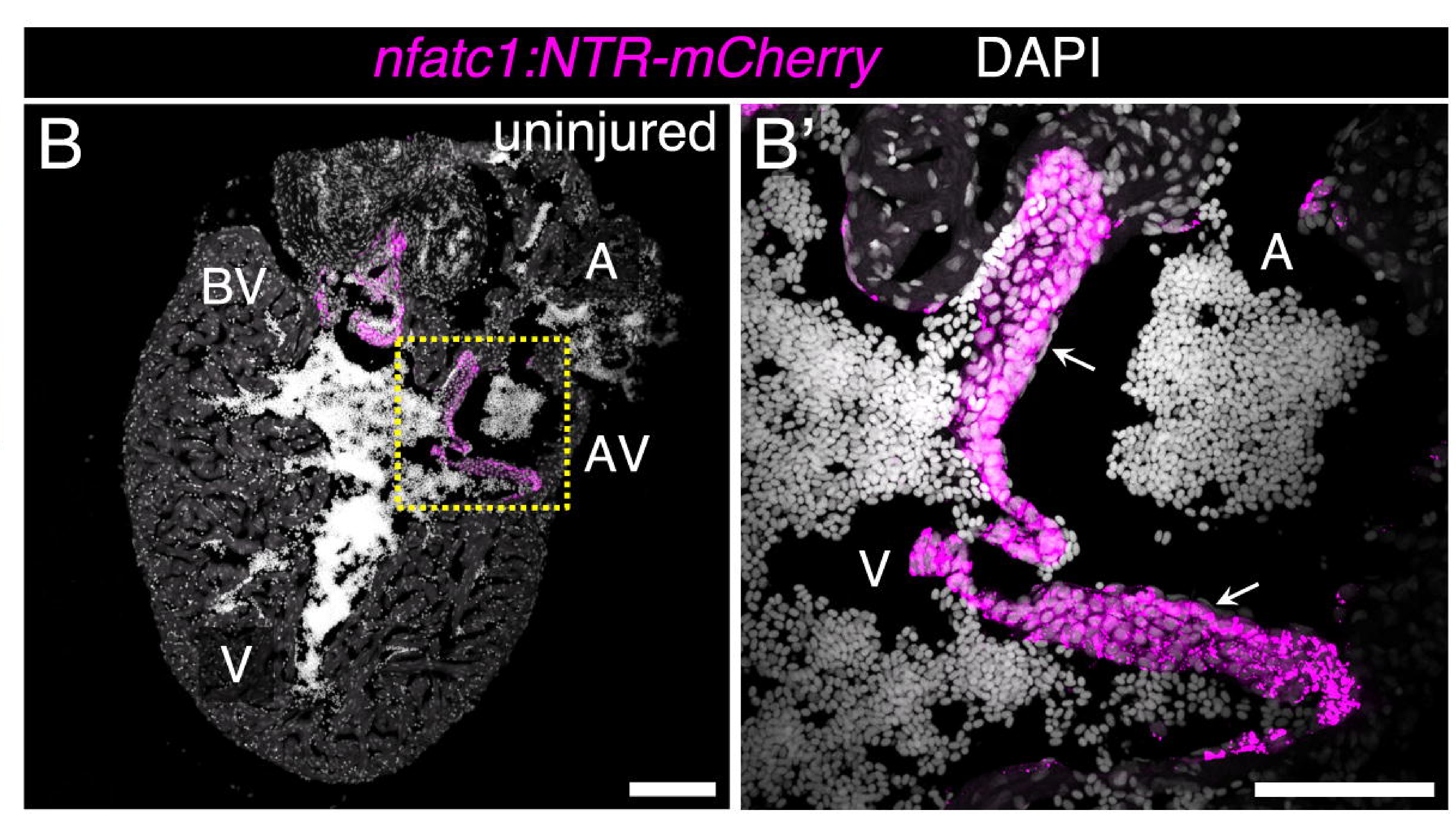

TEM

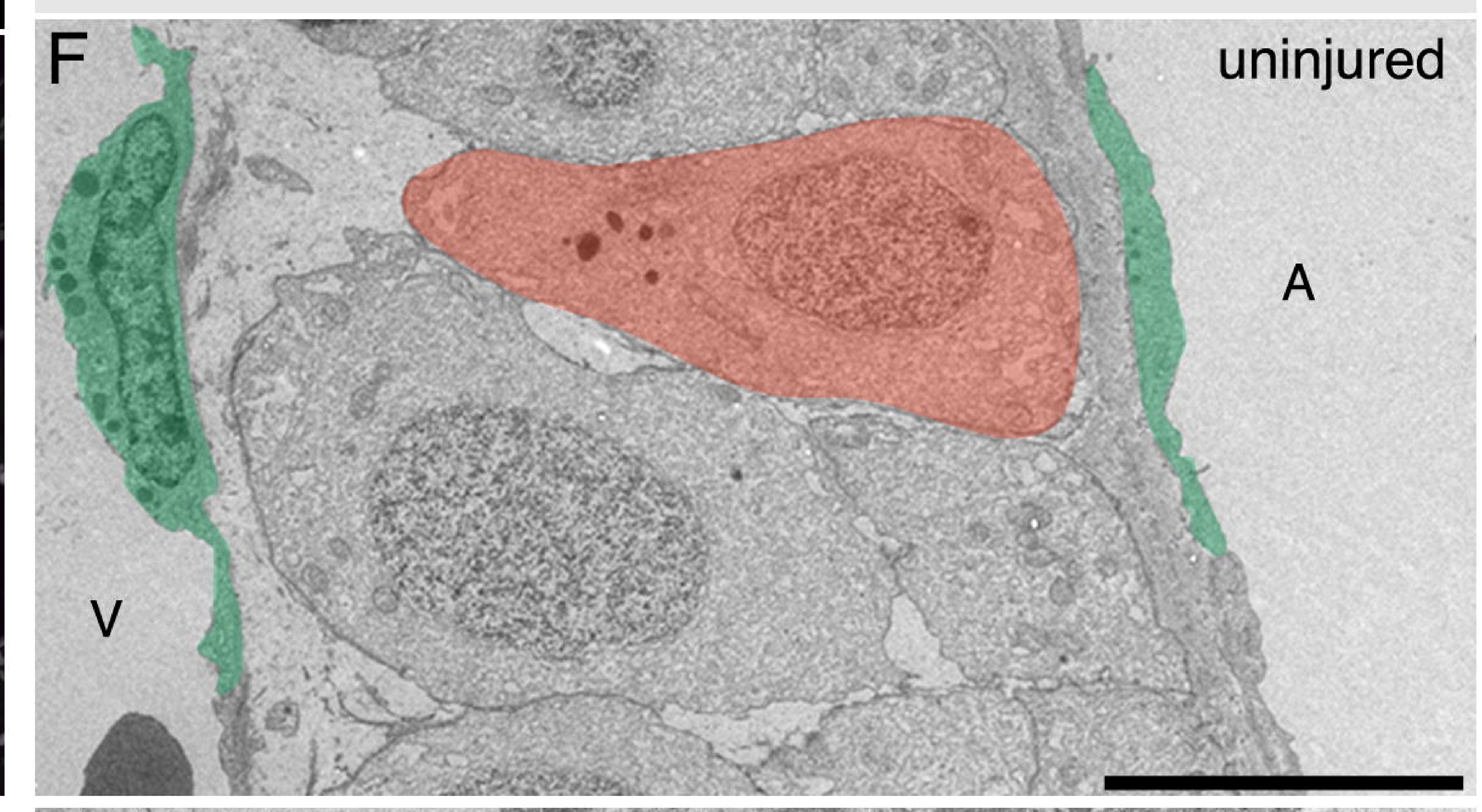

48 hpab

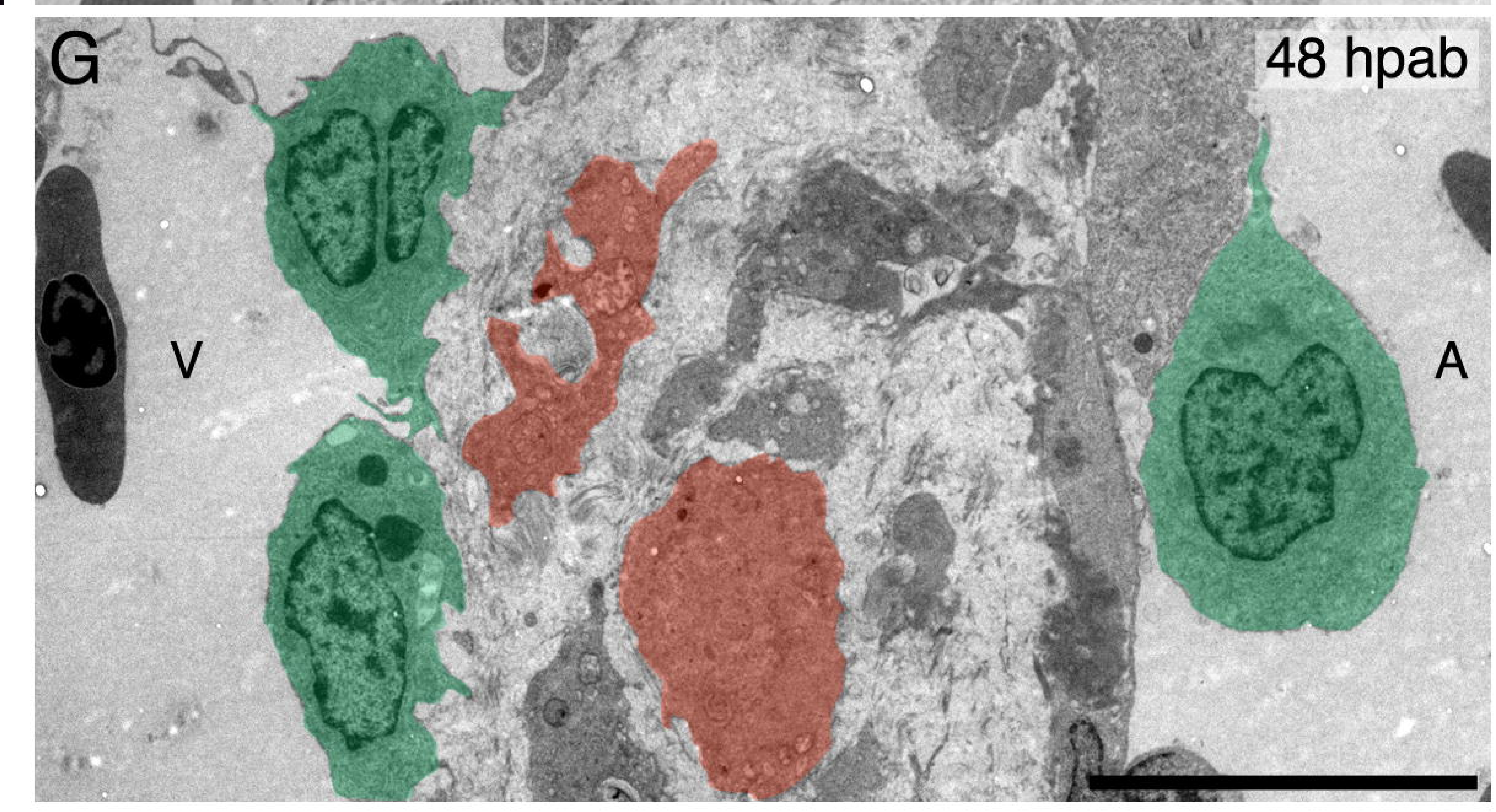

DAPI
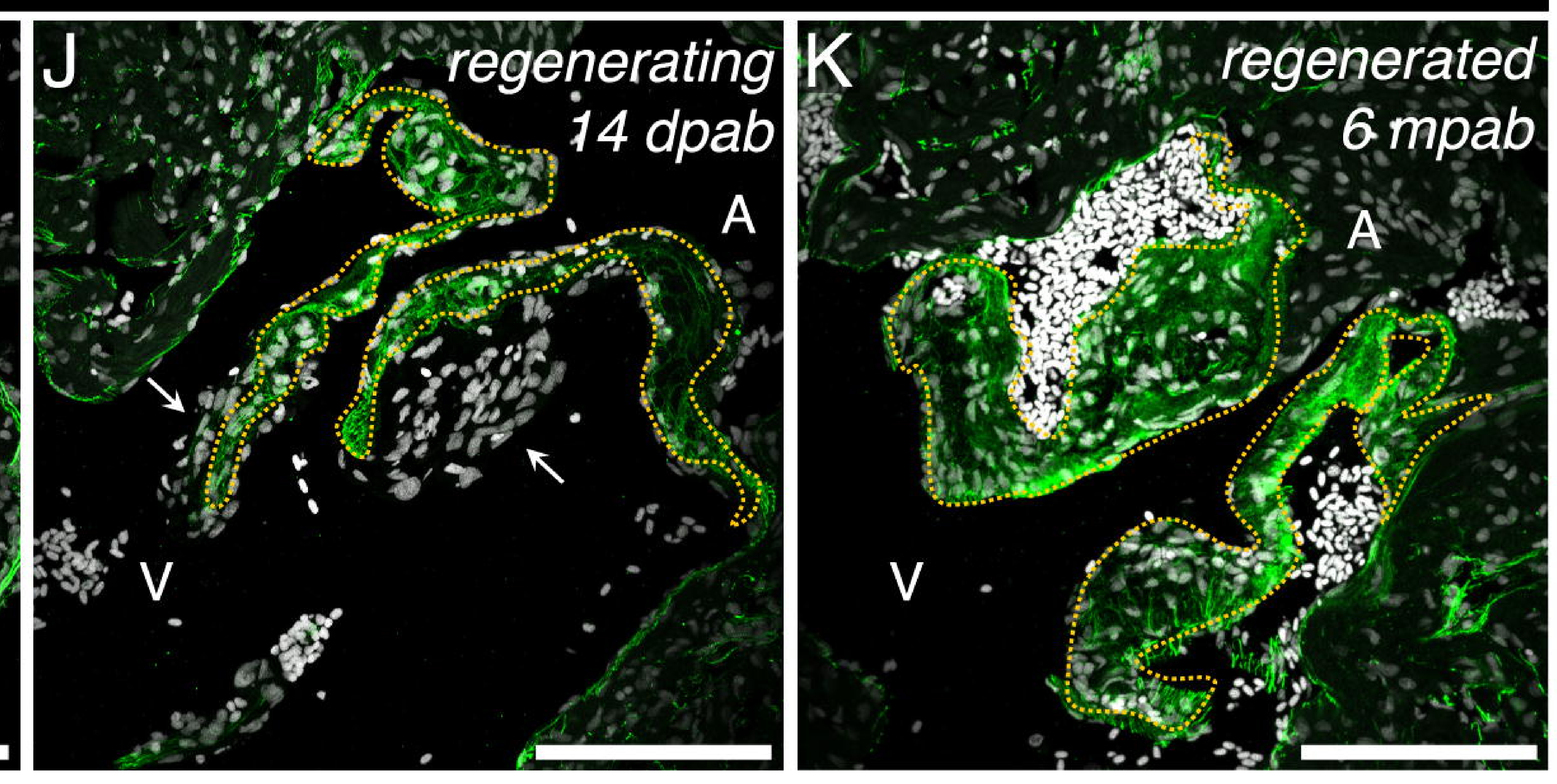





Bensimon-Brito et al., Figure 3

Bensimon-Brito et al., Figure 4

A

B

hsp70:DNalk5a MTZ
C

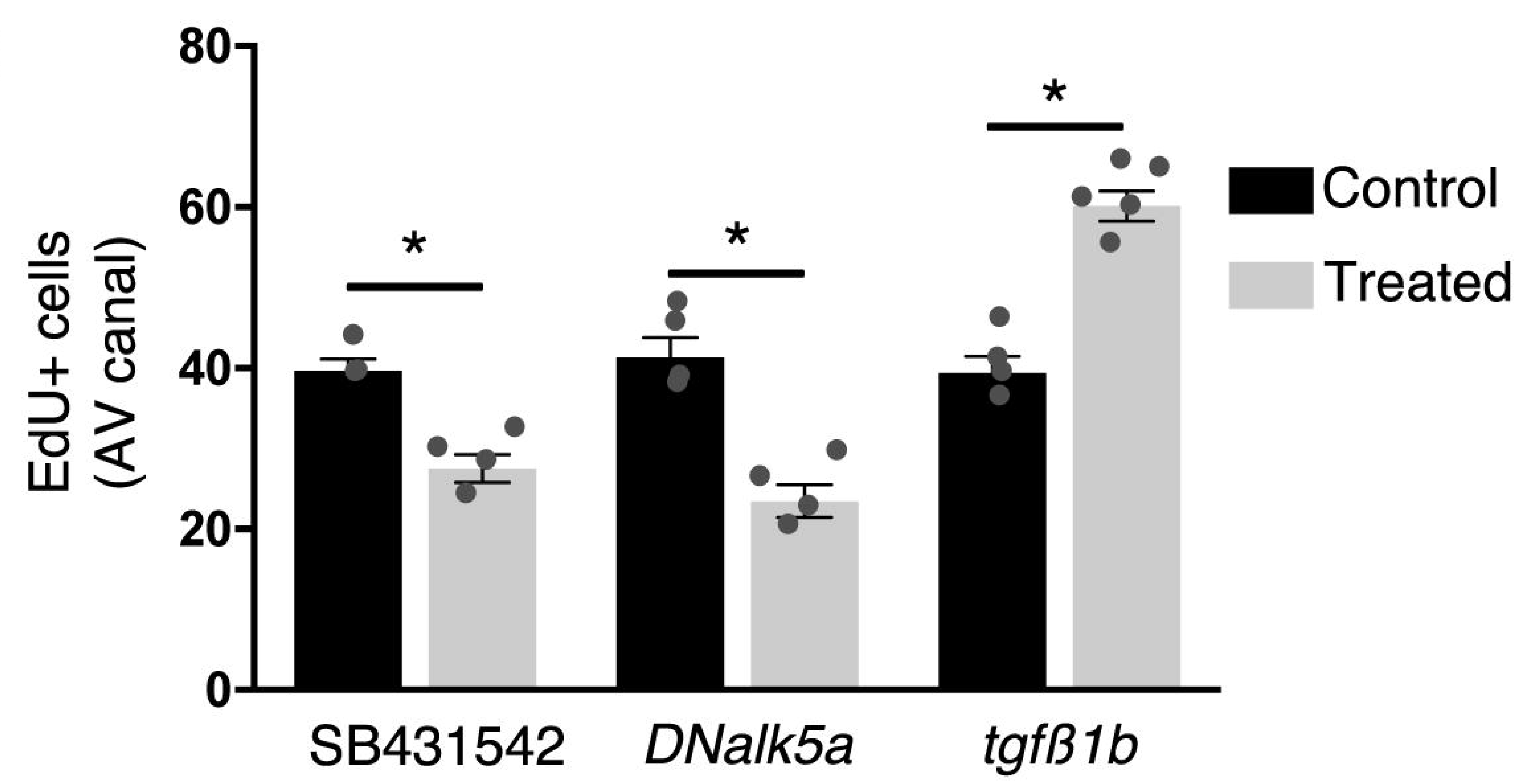

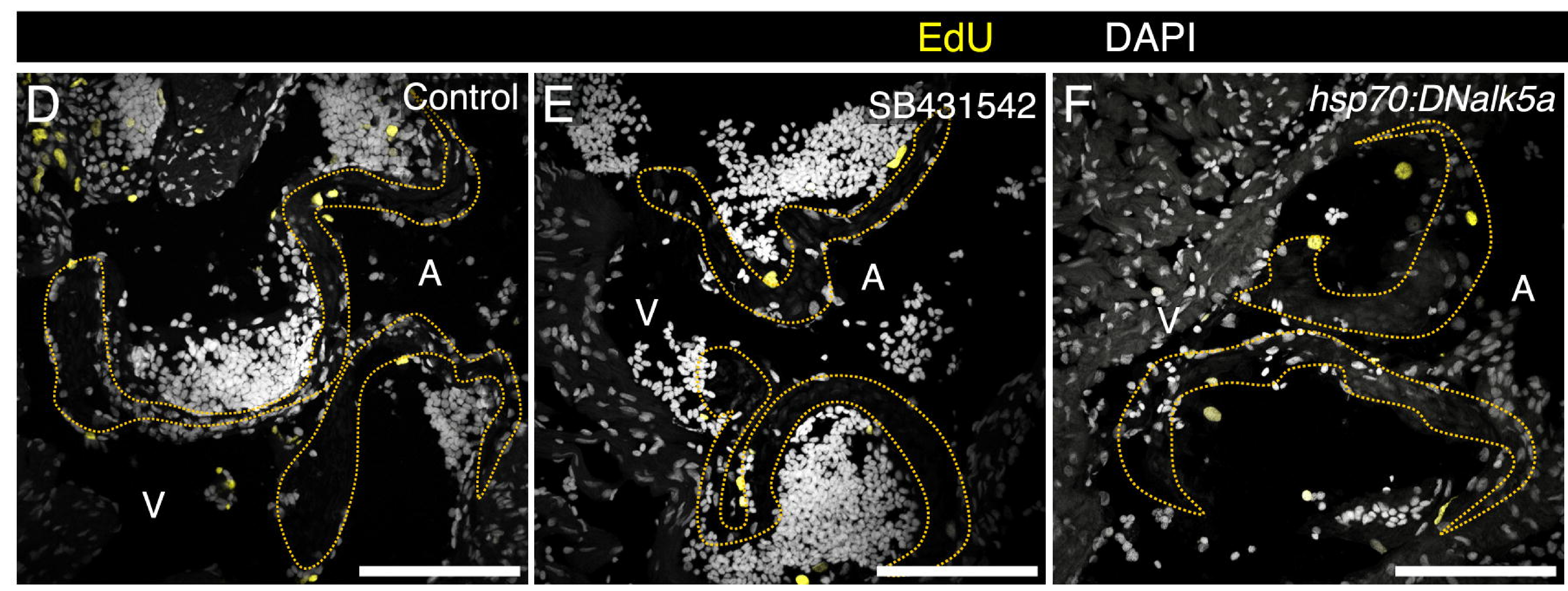

48 hpab

2024

SB431542

48 hpab

nfatc1:NTR-mCherry

DAPI
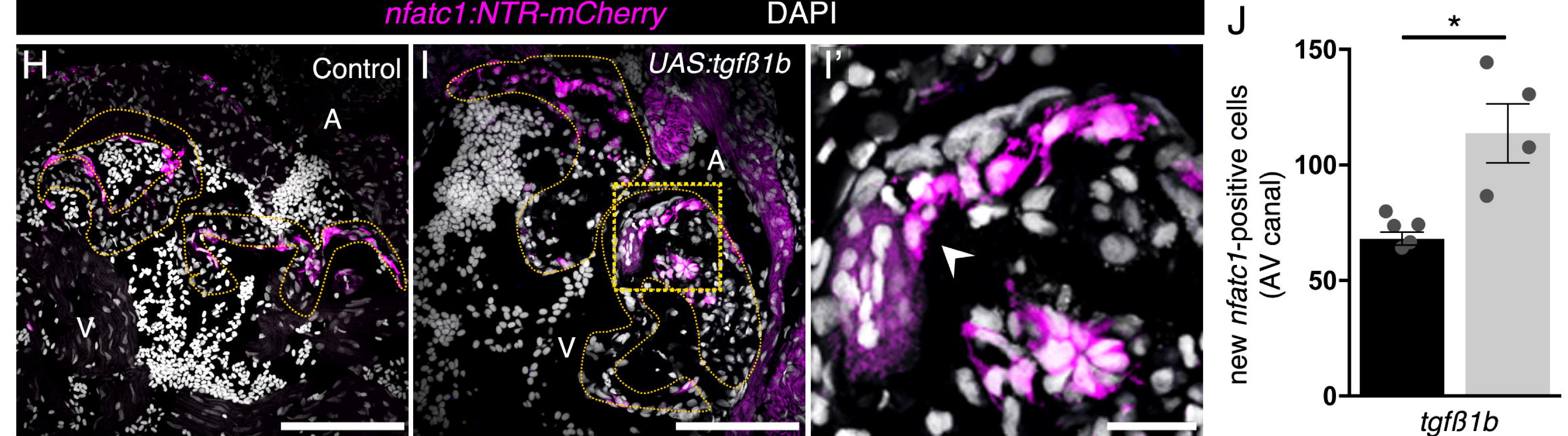

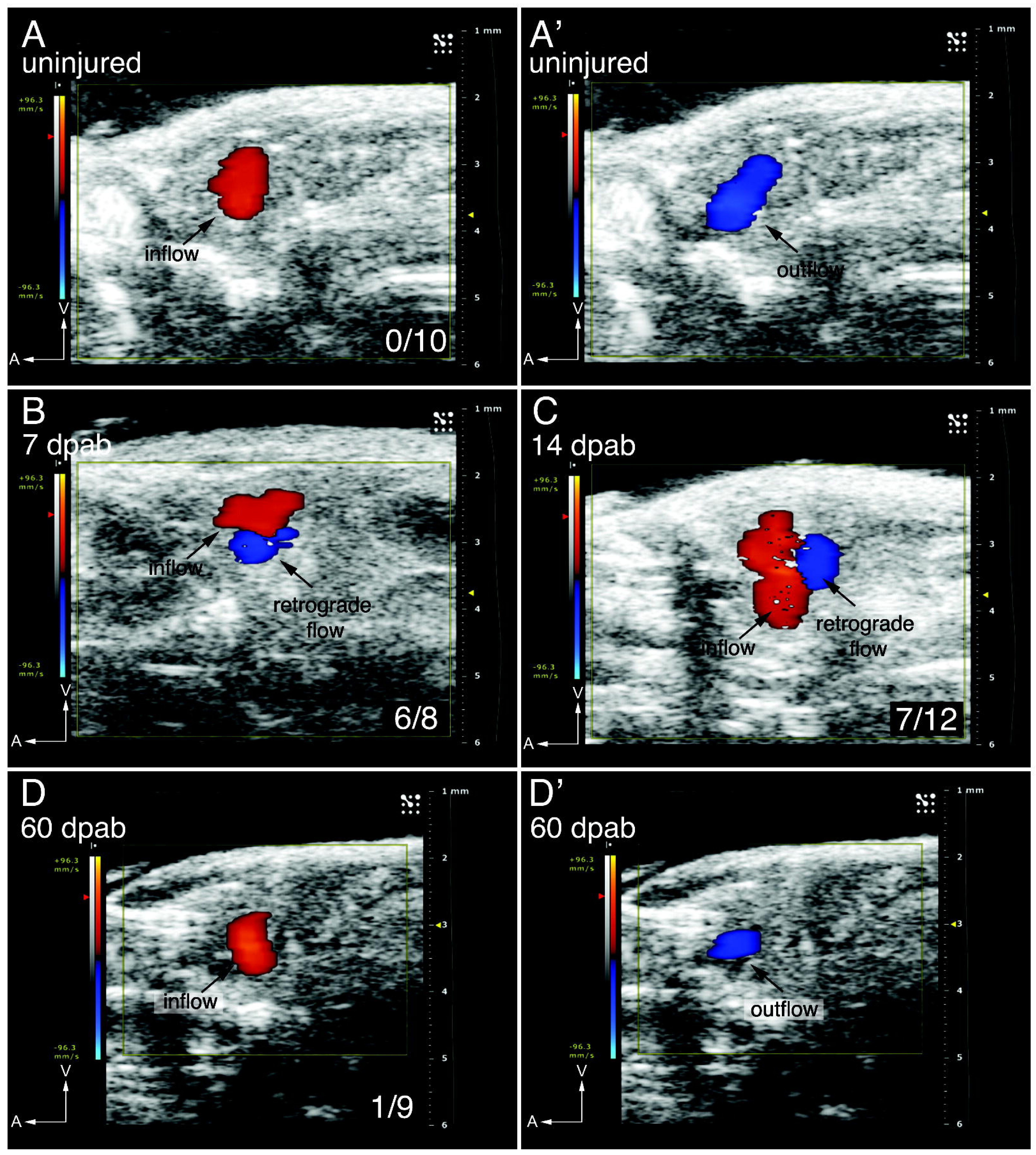
Bensimon-Brito et al., Figure S3






Bensimon-Brito et al., Figure S5

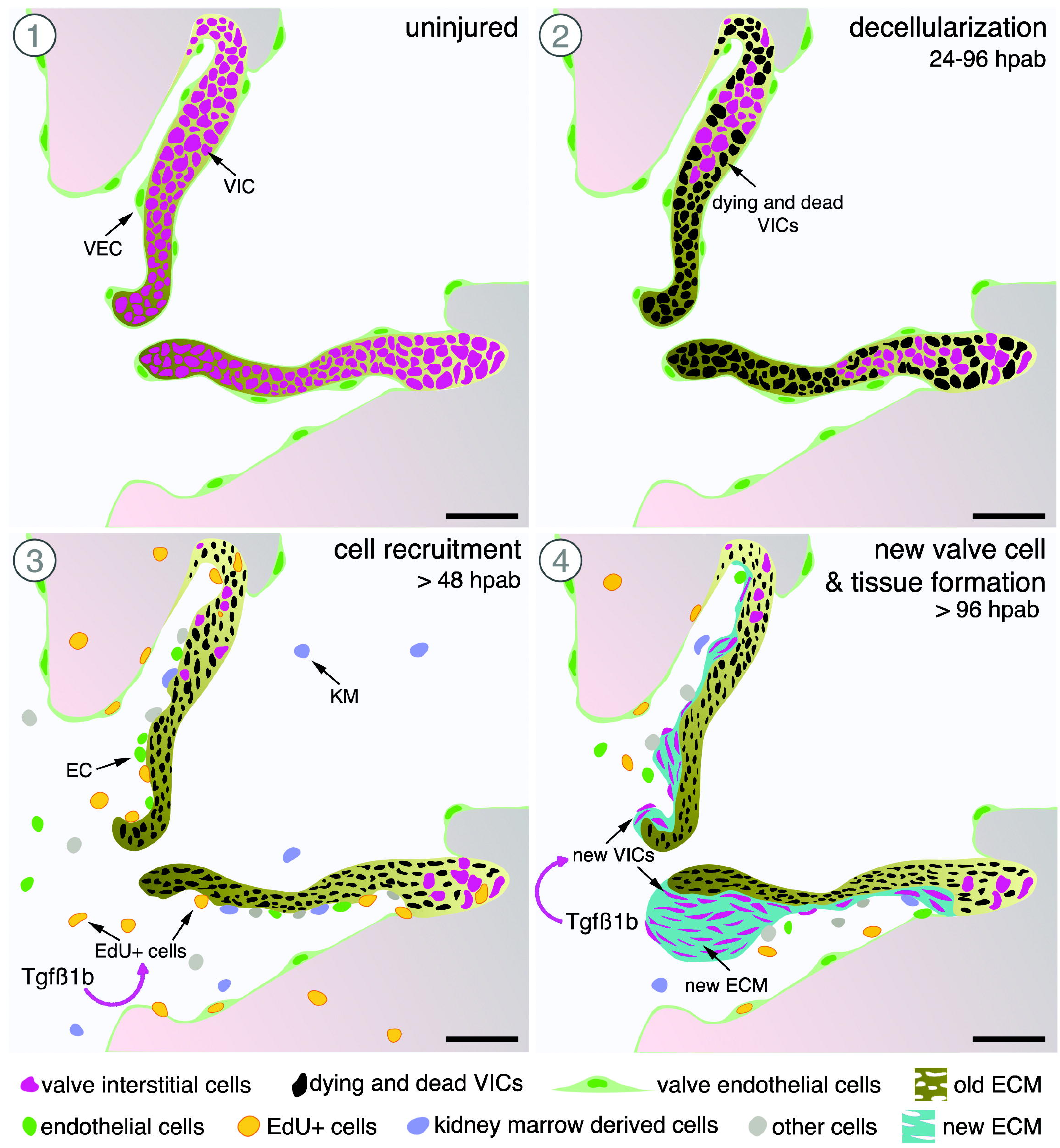

